\title{
ARTICLE
}

\section{Effect of Crianza Positiva e-messaging program on adult-child language interactions}

\author{
Ana Balsa ${ }^{1 \star}$ (D), Florencia López Boo², Juanita Bloomfield ${ }^{1}$, Alejandrina Cristia ${ }^{3}$, \\ Alejandro Cid ${ }^{1}$, María de la Paz Ferro ${ }^{2}$, Rosario Valdés ${ }^{4}$ and María del Luján González ${ }^{5}$ \\ ${ }^{1}$ Department of Economics, Universidad de Montevideo, Montevideo, Uruguay, ${ }^{2}$ Department of Social \\ Protection, Inter-American Development Bank, Washington, DC, USA, ${ }^{3}$ Laboratoire de Sciences \\ Cognitives et Psycholinguistique, Département d'études cognitives, ENS, EHESS, CNRS, PSL University, \\ Paris, France, ${ }^{4}$ Fundación Fe y Alegría, Montevideo, Uruguay and ${ }^{5}$ Department of Psychology, Universidad \\ Católica del Uruguay, Montevideo, Uruguay \\ *Correspondence to: E-mail: abalsa@um.edu.uy
}

(Received 4 December 2020; revised 21 April 2021; accepted 3 August 2021)

\begin{abstract}
We assess the effects of the Crianza Positiva text and audio e-messaging program on caregiver-child language interaction patterns. The program is a six-month-long intervention for families with children aged 0-2 aimed at strengthening parental competences. Its design exploits behavioral tools such as reminders, suggestions of action, and messages of encouragement to reinforce and sustain positive parenting practices. Families in 24 early childhood centers in Uruguay that completed an eight-week workshop were randomized into receiving or not receiving mobile messages. After the program, we videotaped 10-minute sessions of free play between the caregiver and the child, and decoded language patterns using automated techniques. The intervention was successful at improving the quality of parental vocalizations, as measured by the parent's pitch range. We also found suggestive evidence of increases in the duration of adult vocalizations. The results are consistent with more frequent parental self-reported involvement in reading, telling stories, and describing things to the child. Regarding the child, we find a nonrobust decrease in the duration of vocalizations, which we attribute to a crowding-out effect by the caregiver in the context of a fixed 10-minute suggested activity and a more proactive parental role.
\end{abstract}

Keywords: e-messages; parenting; behavioral economics; language; early childhood

JEL Codes: C93; D91; I20

\section{Introduction}

Wide variability in language development is present from very early in life, as early as eight months (Fenson et al., 1994). Early experiences are among the most important predictors of language development, along with maternal education. Research has found that parental interventions that target caregiver's responsiveness and 
communication patterns are effective in changing parental behavior and promoting language development, with some reports of long-term effects on academic achievement and economic outcomes in adulthood (Gertler et al., 2014). However, these programs are, in many cases, resource-intensive and difficult to scale up.

In this article, we evaluate the effects of a low-cost e-messaging intervention directed at parents with children below the age of 2 on the caregiver-child dyad communication patterns. The Crianza Positiva e-messaging intervention consists of a series of text and audio messages delivered to the mobile phones of families three times a week for a period of six months. The messages were designed to complement a parenting workshop of eight weekly sessions. Both the workshop and the messages are organized around four parental competences: attachment bond, protection, stimulation, and reflective function. The messages include reminders, suggestions of simple actions, and messages of encouragement to reinforce and sustain positive parenting practices. Behavioral economics tools have demonstrated large benefits in diverse areas of public policy and are increasingly being used in policies targeting families with children (Gennetian et al., 2016; Mayer et al., 2018; Ajzenman \& Lopez Boo, 2019).

The e-messaging intervention was randomized across 24 early childhood centers in Uruguay that had previously implemented the Crianza Positiva workshop (529 families). All treated and control families participated in the workshop, but only those in the treatment received mobile messages. Bloomfield et al. (2020) analyze the impact of the Crianza Positiva e-messaging program on parental self-reported investment and find that the intervention increased the frequency of parental involvement with the child in social, stimulating, and physical activities by 0.24 SD. It also increased parents' investment quality as measured by a positive parenting index and by an index of outreach for social support.

In this article, we further contribute to the assessment of the program by relying on objective, rather than self-reported, outcomes to study parent-child language interactions. Language development is an important part of the Crianza Positiva curriculum: about $20 \%$ of the messages focus explicitly on promoting parents' involvement in early literacy practices, while the rest seek to improve parental sensitivity and responsiveness, household environment, and the quality of the caregiver-child interactions, all features indirectly associated with better communication patterns and more successful language development (Aboud et al., 2013). Our analysis of language interactions relies on the automated decoding of a 10-minute session of free play between the caregiver and the child, videotaped around three months after the e-messaging intervention ended. The use of externally assessed outcomes mitigates usual problems of self-reports, such as desirability bias.

Our findings show that the intervention was successful at influencing parental language cues: it increased the duration of caregiver vocalizations and improved the quality of vocalizations with an increase of the adult's pitch range. We did not find clear evidence of positive benefits in child outcomes, which may suggest limitations in short free play sessions for assessing language and cognitive development.

Our work contributes to a nascent literature exploiting audio- and text-based communication and behavioral economic insights to boost early literacy development. We believe this is one of the first articles to assess the effectiveness of a large-scale 
e-messaging intervention using automatic decoding of videotapes to infer language and communication patterns. Our results demonstrate the potential of these very lowcost interventions, based on mobile technology and on the understanding of behavioral biases, for changing parental behavioral patterns and ultimately improving child development, particularly when interventions are conducted as a complement to an initial face-to-face intervention with the families.

The article is structured as follows. The section 'Background' provides background literature on interventions that promote language development. The section 'The Crianza Positiva text and audio messaging intervention' describes the Crianza Positiva messaging intervention. The section 'Methodology' provides an overview of the methodology used. The section 'Results' reports our results and in the section 'Discussion and conclusions', we discuss our findings.

\section{Background}

\section{Language development in early childhood}

The importance of language development during early childhood is well known. It predicts the latter results during youth, including literacy skills and school success (Zimmerman et al., 2009; Rowe et al., 2012). It has also been associated with adulthood outcomes, with significant correlations between language difficulties early in life and lower literacy, poor mental health, and higher unemployment rates (Law et al., 2009). A majority of this research has been carried out in North America, but the little evidence that exists from Latin American samples seems to align with the global trends we discuss next (e.g., Law et al., 2009, in Jamaica; Shneidman \& Goldin-Meadow, 2012, in Mexico).

Language development gaps appear early in life. One of the most important predictors of language development is early experiences, along with maternal education. Differences in the rate of language development depend on access to language and gestures from caregivers, and on infant's speech processing skills (Weisleder \& Fernald, 2013). Language inputs and social interactions support the child's language development through opportunities where the child can interpret language and practice his/her emerging skills.

Studies have found a positive association between the quantity of language input and the child's vocabulary and speed of word recognition (Hurtado et al., 2008; Shneidman \& Goldin-Meadow, 2012; Fernald et al., 2013; Weisleder \& Fernald, 2013; Mendive et al., 2020). Furthermore, when studying how the two abovementioned factors work together, Weisleder and Fernald (2013) find that the effect of child-directed speech quantity (language input) on vocabulary is mediated by infants' language processing efficiency. Regarding language input, the evidence points to the conclusion that what matters most for language learning is infant-directed speech and responses contingent on their communicative signals or turn-taking (Snow \& Ferguson, 1977; Weisleder \& Fernald, 2013; Bornstein et al., 2015; Romeo et al., 2018), rather than speech overheard by the child (Weisleder \& Fernald, 2013) or the sheer number of words (Romeo et al., 2018). Caregiver infant-directed speech has been associated with an increased depth of processing in brain imaging 
studies (Zangl \& Mills, 2007) and improved early language skills (Weisleder \& Fernald, 2013; McGillion et al., 2017). In addition, studies have reported a positive association between the number of conversational turns, child language development (Zimmerman et al., 2009), and brain activity (Romeo et al., 2018). A recent study by Rubio-Codina and Grantham-McGregor (2020) shows that the Family Care Indicator (FCI), an index measuring the quality of the home environment in the first years of life, which assesses, among several other resources and caregiving activities, reading, looking at picture books, telling stories, and singing to the child, can predict IQ and academic performance when the child is in elementary school. ${ }^{1}$

Language input has been linked to household socioeconomic status (SES). For the USA, Hart and Risley (1995) found that children in low-income households not only heard fewer words per hour from their caregiver than children in high-income households, but the content also varied greatly between groups. The difference they found meant that by age 4 , children in high-income families will have been exposed to 30 million more words than children from low-income families. A more recent study found that associations between vocabulary and language processing efficiency, and SES, appear as early as 18 months, and that this association is pronounced by the time the child turns two (Fernald et al., 2013). In Latin America, language disparities widen with age and are also associated with SES (Berlinski \& Schady, 2015). There is also evidence from Uruguay on SES gradients on the home environment and the FCI (Lopez Boo et al., 2018).

Other authors have reported large variance in language input and infants' language development within households of homogeneous socioeconomic characteristics (Weisleder \& Fernald, 2013), as well as associations over and above SES (Zimmerman et al., 2009; Romeo et al., 2018), suggesting that SES by itself does not determine the infant language trajectory. Sperry et al. (2019) test Hart and Risley's (1995) (HR) findings using data from five communities in the USA. Their results do not support HR findings: they do not find a clear pattern between the number of words spoken by the primary caregiver to the child and SES. Even when testing for a broader definition of the child's verbal environment (all speech directed to the child and speech heard by the child), they still do not find a consistent relation between these measures and SES.

Either way, creating language-rich experiences for children is extremely important to prevent language disparities that continue throughout the life cycle. Parental interventions that target caregivers' responsiveness and communication patterns have been found to be effective. For example, a six-month home-visiting program (3Ts: Tune In, Talk More, and Take Turns with the child) for low SES households in the USA that focuses on the home language environment had immediate positive effects on caregivers' knowledge, the quantity of linguistic input, and the quality of caregiver interactions (Leung et al., 2020). Some aspects of the intervention that the researchers

\footnotetext{
${ }^{1}$ Most of the referenced studies analyze populations from developed countries (the USA or the UK) of varied SES. Some exceptions are Snow and Ferguson (1977) that analyze populations from mostly developed and a few less-developed countries; Mendive et al. (2020), that study a varied SES population in Chile; and Rubio-Codina and Grantham-McGregor (2020), who work with a low- and middle-income population in Colombia.
} 
point out as being key to effectively changing parents' behavior at home are video modeling (strategies are presented through true-to-life videos), concrete feedback (based on quantitative measures of linguistic input from LENA ${ }^{2}$ recordings), and goal setting (goals are set in terms of the linguistic input measures collected from the previous week).

McGillion et al. (2017) evaluate another language intervention that focuses on contingent talk and find immediate effects on caregivers. Households are visited twice in a two-week period. In the first visit, the importance of contingent talk is introduced, a short video with examples is presented, and caregivers are asked to set aside 15 minutes per day to practice what was learned. In the second visit, further questions are solved. Immediately after the end of the intervention, the study finds that parents assigned to the intervention engage in more contingent talk. However, a year later, no effects are found. This fade-out suggests the importance of guiding and providing the caregivers with more tools to effectively support the infant's language learning through the different stages of its development.

A recent set of studies evaluates the incorporation of technology in early childhood interventions that promote literacy skills. Doss et al. (2019) evaluate 'Ready for K!', a text-based intervention in the USA to help parents support their preschoolers' development. The program increased parental involvement at home and at the school and improved child literacy skills. Doss et al. (2019) show that personalizing 'Ready for K!' messages increases the likelihood that parents read to their children by $50 \%$. Hurwitz et al. (2015) and Meuwissen et al. (2017) also report that the use of text messages increased parental engagement in literacy and other learning activities with their children. Mayer et al. (2018) evaluate an intervention that provided parents with a tablet containing children's books and a goal-setting tool, reminders, and social gratification messages. The authors find that parents in the treatment group used the tablet more and read more to their children.

\section{Measurement of language input and output}

In the economics literature, the norm has been to use standardized tests, such as Bayley Scales (Bayley, 1969), the Denver Developmental Screening Test (Frankenburg et al., 1992), and MacArthur Communicative Development Inventory (Fenson et al., 1993), to measure early language development. We know these measures are predictive of future outcomes (Fernald et al., 2009) and that early stimulation strongly impacts language as measured by these tests (NICHD, 2000; Rubio-Codina \& Grantham-McGregor, 2020). However, these measures are subject to limitations including the fact that they are expensive to implement, depend on evaluators' training and profile, and measure the child's development in a particular setting. An alternative to standardized development tests is audio recordings that measure the child's language skills in a natural setting in addition to collecting other measures, such as maternal vocabulary and conversational turns. These audio recordings are usually

\footnotetext{
${ }^{2}$ The Language ENvironment Analysis (LENA) system is a relatively new recording technology that can be used to investigate typical child language acquisition. More details can be found here: https://www.lena. org/.
} 
obtained without the mediation of a trained facilitator and provide critical information for understanding the infant's language trajectory and environment.

There are broadly two methods to capture both the quantity and quality of language input and output through recording, namely short audio- or video recordings, or day-long audio recordings (Lavechin et al., 2021). In the psycholinguistic literature, it is most common for the former to be transcribed by trained annotators, and for the latter to be analyzed automatically, typically using speech technology algorithms that do not produce orthographic transcriptions (not technically possible today), but which instead provide estimates of who spoke when and for how long (e.g., Zimmerman et al., 2009). Human transcription of adult speech in such conversations is a time-consuming process, with most annotators requiring 20 times the recording duration, that is, 1 minute of interaction takes 20 minutes to transcribe. Transcription is even more time-consuming for speech by children aged 1-3 years, with estimates for transcription time reaching 40 times the recording duration. It is beyond the scope of this article to fully lay out the advantages and disadvantages of short versus long recordings, but we do point out that day-long recordings remain quite challenging to collect in large-scale projects like ours because of logistical, legal, cost, and ethical reasons, which led us to prioritize short observations. We believe our study is among a few to analyze the impact of a behavioral and parenting intervention at scale and measure language outcomes using short videotaped recordings (a cost-effective method vis-à-vis day-long recordings). ${ }^{3}$

In short video- or audio-recorded observations, the quantity of a caregiver's speech can be measured in terms of the number of words, number of vocalizations, or amount of time spoken. We are not aware of research showing that longer vocalization durations correlate with child development in short observations, but in transcription-based research, children who are more advanced produce more vocalizations (Gilkerson et al., 2017) and utterances with more words (i.e., with a higher 'mean length of utterance', e.g., Allen \& Dench, 2015), which, all else equal, should be correlated with greater child vocalization duration. We also expect more parental input (a longer duration of parental vocalizations) to have a positive impact on the child (e.g., Ferjan Ramírez et al., 2019, 2020).

Communication quality, on the other hand, may be captured through the number of conversational turns, parental responsiveness, and the caregiver's pitch. A child is more likely to be engaged when the conversation takes place in turns rather than when the caregiver talks nonstop. There is research also suggesting that more responsive caregivers, who vocalize after the child vocalized, help yield better language outcomes in day-long recording data (Ferjan Ramírez et al., 2020). Another way to engage the child is via producing speech that captures the child's attention. This is often done by using a child-directed speech register (or Parentese speech), characterized by a higher pitch (and in some cultures, a larger pitch range) than adult-directed

\footnotetext{
${ }^{3}$ Some previous evaluations of parenting programs such as Rodriguez et al. (2010) for Health Families New York, Love et al. (2005) for Early Head Start, and Olds et al. (2004) for Nurse Family Partnership have used measurements based on video recordings to analyze mother-child interactions, which could, thus, provide a view both on input and on child output. More recently, Conti et al. (2020) also used 3-minute videotaped play sessions to evaluate a home-visiting program in Germany and focused on reciprocity and the initiation of interactions.
} 
speech. It is, in part, because of the higher pitch and larger pitch range that infants show a strong preference for infant- over adult-directed speech (Fernald \& Kuhl, 1987; The ManyBabies Consortium, 2020), and this heightened attention boosts performance in a wide range of tasks (a systematic review in Cristia, 2013). Caregivers can be trained to use this register, leading to positive child outcomes (Ferjan Ramírez et al., 2019, 2020).

\section{The Crianza Positiva text and audio messaging intervention}

The Crianza Positiva text and audio program is a six-month-long intervention for families with children aged 0-2 years. Messages were designed to help caregivers change their decision-making strategies in order to adopt what previous research suggests to be positive parenting practices and sustain these practices over time, to ultimately change their children's development. Participant families started receiving messages right after completing a workshop of eight weekly sessions that was organized around four parenting competences: attachment bond, stimulation, protection, and reflective function. Families in the treatment group received messages three times a week both in text (via SMS) and in audio format (via WhatsApp). The contents of the text and audio messages were exactly the same, except for the fact that text messages were personalized with the name and gender of the child. Control families received a single SMS message thanking them for their participation in the workshop.

The message structure is based on behavioral economics insights. Its design recognizes the existence of four key behavioral biases associated with low parental investment. First, parents' behavior may be influenced by the present bias (Thaler, 2015), which implies attaching low valuation to costly activities that imply rewards only in the future. Another key bias is limited attention and cognitive fatigue as it deviates cognitive resources from important decisions (Shah et al., 2012; Mani et al., 2013; Schilbach et al., 2016) such as those relating to parenting. Lastly, negative identities can lead to suboptimal parental investment by making parents attach a low value to their existing resources and individual performance. Having a positive identity as a parent is important because self-esteem can increase effort through higher levels of motivation (Bénabou \& Tirole, 2002).

As stated above, the literature on language development highlights the importance of exposing the child to language stimulation in the context of a sensitive and caring interaction. Throughout the program, several modules of messages focus on providing the right setting for an adequate development of literacy skills. A first module promotes parental sensitive observation, interpretation, and response to the child's needs and signals, gentle treatment, and the expression of affection (17\% of the messages). This module emphasizes observing the child carefully, trying to interpret his/her expressions, gestures, and signals, seeking to understand what the child is feeling and thinking, exploring how to get closer to the child by responding to these signals, demonstrating love, and communicating assertively. A second module explicitly emphasizes the benefits of parental involvement in specific home-literary practices (17\% of messages) and suggests concrete activities, such as engaging in conversations with the child, asking open questions, describing objects, places and activities, singing and listening to songs together, and engaging in book-reading and story-telling 
routines. The rest of the modules cover other parenting practices such as child safety at home and the incorporation of routines (17\% of messages), free play and parental involvement in enjoyable activities with the child (17\%), and parental self-care and reflective function (32\%). To the extent that all messages influence the quality of the environment and of the parent-child interaction, they are directly or indirectly setting the grounds for better communication patterns and improved language development.

Treated families receive messages three times a week at the same time (specifically, Mondays, Tuesdays, and Fridays at $6 \mathrm{pm}$ ). A fundamental challenge of home visits and other interventions seeking to improve parenting practices is to be able to help parents overcome potential behavioral barriers they face at home in key moments when parenting decisions are critical. The message structure is designed to address some of these biases and always follows the same pattern. On Mondays, families receive a message with information on the benefits to the child of engaging in a certain parenting practice. This message aims at addressing present bias and inattention. Reminders have been successfully implemented in many contexts (from reminding people about voting to reducing missed appointments in hospitals or increasing medication adherence) and work well especially if the timing is right (Dale \& Strauss, 2009; Gurol-Urganci et al., 2013).

On Tuesdays, families receive a suggestion to engage in a specific activity with the child in relation to that week's topic and to repeat it during the week. This activity does not take much time and is usually concrete and easy to implement. The purpose of this message is to simplify parental decision-making in the face of the complexity of parenting and to help parents establish routines by engaging repetitively in the mentioned practices. The message addresses inattention and cognitive fatigue. Doss et al. (2019) show that providing activity tips to parents can help reduce parental cognitive load and improve parental ability to process information, particularly in the context of highly stressful environments.

On Fridays, families are invited to reflect on their performance during the week and on their personal feelings regarding the task proposed and usually receive a motivational or encouragement message. This message seeks to help parents overcome negative identities and strengthen self-efficacy.

For example, during the week that focused on vocabulary development and the importance of speaking to the child, parents received the following messages:

\section{MONDAY:}

Children's brains are like sponges, they absorb everything: the sounds, the pitches of voices, the language they listen to. The more words your child listens to at this stage, the more [she] will develop [her] language. It is therefore very important that you speak to [child's name], this will impact heavily on [her] ability to learn.

\section{TUESDAY:}

Take advantage of every moment to tell [child's name] what you're doing when you're with [her]. For example, say 'I'm changing your diapers', 'Now I'm preparing the food', or 'Let's go for a walk'. This will help enrich [her] language. 


\section{FRIDAY:}

The more you speak to [child's name], the better will [her] language develop and the more [she] will learn. Today and in the following days, remember and repeat this thought: 'I take advantage of all the moments with [child's name] to speak to [her].'

The program included some additional components that provided parents with further sources of information and material. For example, we coupled messages promoting reading and singing to the child with a message that provided a username and password to access 'Radio Butiá, a Uruguayan web server that hosts Latin American songs and stories online. These messages addressed concerns relating to the possibility that families without children's books and music would not perform the suggested activities.

\section{Methodology}

\section{Timeline and main features of program implementation and evaluation}

Participant families were selected from a pool of candidates who had attended an eightweek parenting workshop at 'Children and Family Care Centers' (CAIF) of Uruguay. After workshop completion, in December 2017, we assigned families to a treatment and control group to evaluate the effects of the Crianza Positiva text and audio messages component. Following Baird et al. (2018), we selected a two-stage randomization strategy in order to measure spillovers. First, we stratified the sample by average maternal education and, within each stratum, randomly allocated early childhood centers to receive or not receive messages using a $60-40 \%$ rule. As a result of the randomization, we assigned 14 early childhood centers to the treatment group and 10 centers to the control group. Next, within each center in the treatment arm, we randomized families into receiving or not receiving messages. In centers that were treated, $80 \%$ of families were selected to receive messages. Out of the initial 529 families, 237 families were assigned to receive messages, 59 were assigned not to receive messages but belonged to a treated center, and 233 families were assigned to a pure control group.

Figure 1 illustrates the timeline of the implementation and evaluation of the Crianza Positiva messaging program. Treated families received messages between January 5, 2018, and June 27, 2018, and control families received a single SMS message on January 26, 2018, thanking them for participating in the parenting workshop.

Messages were sent to all contact numbers we had for each family (mothers, fathers, and other caregivers), which in total added to 373 mobile phones. SMS (text) messages were sent through a platform that enabled us to personalize the messages by including the name of the baby and gender-specific pronouns. We also created a WhatsApp broadcast list to deliver text and audio messages. ${ }^{4}$

We collected data on families' SES and other characteristics at three points in time. Baseline information was collected before the initiation of the workshops (in August 2017) and after the workshop ended (November-December 2017). We conducted a

\footnotetext{
${ }^{4}$ Due to the specificities of WhatsApp, only mobile phones that saved the mobile number of Crianza Positiva received the messages. In our welcome message, we asked families to add our cellphone to their contact list.
} 


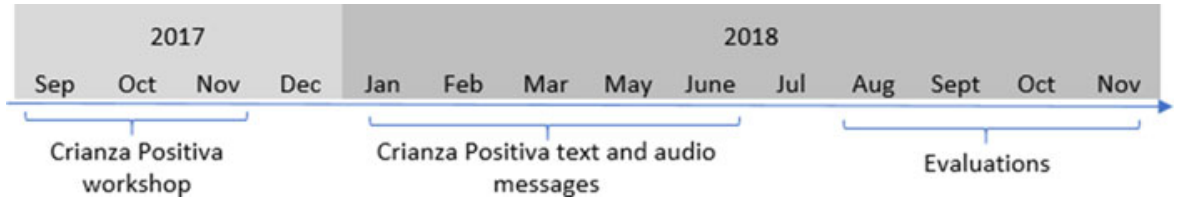

Figure 1. Crianza Positiva Timeline.

follow-up assessment two months after the messaging intervention ended (between August and November 2018). Baseline evaluations were carried out at the CAIF center, and follow-up evaluations were carried out either at the family's home or at the center depending on the family's preferences. ${ }^{5}$ In this article, we focus on a specific component of the family assessment: a 10-minute video recording of the interaction between the caregiver and the child in a free play activity. Evaluators (most of them psychologists, therapists or social workers, or advanced students of these specialties) provided the dyad with a set of toys that they could use during the activity. The mother received instructions to play freely while being recorded. The evaluator was instructed not to interfere.

\section{Outcomes}

The first set of outcomes we consider includes the counts and duration of vocalizations for both the child and the adult. A vocalization is a section of audio that has been classified automatically as being speech-like and attributed to an adult or a child. ${ }^{6}$ As summarized in the section 'Measurement of language input and output', previous research suggests that better input is associated with more and/or longer child-directed caregiver vocalizations (e.g., Ferjan Ramírez et al., 2019, 2020). As for the child, more advanced children produce more vocalizations (Gilkerson et al., 2017) and potentially longer ones (Allen \& Dench, 2015).

Second, we capture communication quality through the number of conversational turns between child and adult. There is a turn whenever there is a threshold of at most 0.3 seconds between a vocalization offset and the next vocalization's onset. We also account for parental responsiveness by considering the proportion of child vocalizations that are followed by an adult vocalization in less than 2 seconds (adult response ratio). If the intervention improves communication quality, this may be reflected in higher turn counts and higher adult response ratios in the treatment compared with the controlled group (see the section 'Measurement of language input and output').

Finally, we account for two qualitative measures of adult vocalizations: pitch range and pitch average. Fundamental frequency $(f 0)$ range is the difference between the highest and the lowest $f 0$ frequency reached within a given vocalization. The $f 0$ average is the average pitch of that vocalization. Research summarized in the section 'Measurement of language input and output' leads to the prediction that caregivers

${ }^{5}$ This was a family choice and was unrelated to treatment status.

${ }^{6}$ The speech detection software is unable to classify overlapping speech. 
in the treatment group should exhibit higher pitch and larger pitch ranges than caregivers in the control group.

All outcomes were obtained from automatic analyses of the 10-minute videos using the DiViMe open-source package (Le Franc et al., 2018) via the avutils package (Neumann, 2020). For the main outcomes, we first conducted manual annotations of the outcome for a random set of 30 videos and then checked the Pearson correlation between the manual and the automatic annotations. These correlations are reported in Figures A1 to A6 in Appendix 1. This allowed us to select the DiViMe diarizer (and parameters such as interturn duration) leading to the best performance. We used the Yunitate broad class diarizer, a recurrent neural network that has been trained to classify audio into three broad classes: male adult, female adult, and child. With this diarizer, we find correlations of $r=0.78$ between manual and automatic child vocalization counts, of $r=0.64$ for child vocalization durations, and of $r=0.77$ for conversational turns. The correlations between manual and automatic annotations for adult vocalizations are $r=0.74$ for vocalization counts, $r=0.66$ for vocalization duration, and $r=0.7$ for adult response rate within 2 seconds. Correlations are measures of association between two variables; a correlation of 0.7 is very high (given Cohen's 1988 guidelines, where correlations above $r=0.5$ are 'large'), and it indicates that the two variables share $70 \%$ of the variance.

Because child language may be difficult to assess at these ages, we correlated child outcomes with age in months. We expected that child measurements should correlate with age, because we would like them to be sensitive to language development and age is a good proxy for development (older children have better language than younger children). Unfortunately, we did not find a statistically significant correlation between count or duration of child vocalizations and child's age. This raises some concerns about our ability to measure children's language outcomes with precision. We did find, however, a negative correlation between the duration of adult vocalizations and children's age $(r=-0.11 ; \mathrm{p}<0.1)$, suggesting that adults vocalize less as children vocalize more in the context of the proposed fixed time activity, and that the measures of adult vocalizations may be more reliable than those of the child. We found no association between maternal age or education and language outcomes.

\section{Compliance}

Issues like having the incorrect mobile number or sending messages to a line that is unavailable or has no credit could lead to SMS failure. In our intervention, we sent messages via SMS and WhatsApp to reduce concerns that this could happen. One month after program initiation, we recontacted all treated families to verify whether they were receiving the SMS messages. We repeated this for a random sample of treated families three months after program initiation. We learnt from these follow-ups that out of the 237 families in the treatment group, 197 were receiving SMSs correctly, while 40 were not. We asked the CAIF centers to provide us with new contact numbers of these families. We could update nine contact numbers, which reduced our SMS failure rate to $13 \%$. WhatsApp messages had a high reception rate: in $87 \%$ of families at least one family member received the messages. The percentage of families 
that read the messages was also high: families that received the messages read on average $69 \%$ of them. Overall, we found that 27 out of the 237 families assigned to treatment did not get SMS nor WhatsApp messages. The correlation between assignment to the messaging treatment and receiving the messages was $r=0.9$.

\section{Attrition and balance}

We managed to collect videos on $50 \%$ of the 529 families at baseline (either in August or in November-December 2017) and on 60\% of the families at follow-up (317 families overall, 122 assigned to receive messages and 195 in the control group). During baseline, control families were less likely than treated ones to consent to being videotaped, while the opposite was true at follow-up. We ended up with 178 families (34\%) with a recorded video both at baseline and at follow-up, 80 of which were in the messaging treatment group and 98 in the control group. ${ }^{7}$ There was no differential attrition in these families across treatment and control arm.

Based on WhatsApp message reception markers, $80 \%$ of treated families with a video at follow-up read or listened to the WhatsApp messages at least once. Among these, families opened, on average, $79 \%$ of the messages. Regarding families with videos at baseline and follow-up, $85 \%$ read or opened at least one WhatsApp message, and on average, they opened $83 \%$ of the messages.

Table 1 reports descriptive statistics of family characteristics at baseline as well as the balance of these characteristics across treated and control subjects (ITT $=1$ and ITT $=0$, respectively ${ }^{8}$ ), both for the sample of families with videos at baseline and follow-up and for the sample only with a video recorded at follow-up. Regarding the first sample (see columns (1) through (3)), more than $90 \%$ of caregivers correspond to the child's mother. The average age of the mother is around 30 years old, nearly half of the children are male, around $11 \%$ were born premature, and $20 \%$ are still being breastfed. Three out of four children live in a family with both their biological parents. On average children live with another sibling in the house, and $15 \%$ live with other adults. We constructed a wealth index that was a weighted average of household assets, with the weight of each asset in inverse proportion to its availability across households. The index is skewed to the left: within a range of $0-1$, the average household has an index value of 0.25 . Two out of three households receive governmental assistance, and $85 \%$ report having participated in at least six of the eight Crianza Positiva workshop sessions. Twenty-nine percent of mothers completed middle school, but not high school, and another $28 \%$ completed high school or more. This implies that more than $40 \%$ of mothers have less than middle school. Forty percent of mothers work full time, around $20 \%$ work part time, and $80 \%$ of fathers have a full-time job. Half of the families suffered a negative shock in the 12 months prior to the baseline survey, such as a divorce, a death, a job dismissal, or a disease within the family, among other issues.

\footnotetext{
${ }^{7}$ Eighteen of these were control families were within treated centers.

${ }^{8} \mathrm{ITT}=1$ whenever the family is assigned to receive messages. It is 0 when the family participates in a center not assigned to be a part of the treatment, or participates in a center selected for treatment, but is not assigned to receive messages.
} 
Table 1. Descriptive statistics and balance of family characteristics at baseline

\begin{tabular}{|c|c|c|c|c|c|c|}
\hline & \multicolumn{3}{|c|}{ Sample with videos at baseline and follow-up } & \multicolumn{3}{|c|}{ Sample with videos at follow-up } \\
\hline & (1) & (2) & (3) & (4) & (5) & (6) \\
\hline Probability of being videotaped & 0.34 & 0.34 & 0.002 & 0.67 & 0.52 & $-0.153^{\star \star \star}$ \\
\hline \multicolumn{7}{|l|}{ Family characteristics } \\
\hline Child's gender & 0.47 & 0.50 & 0.031 & 0.49 & 0.48 & -0.017 \\
\hline Child's age in months by January 1, 2018 & $25.49(5.02)$ & $24.76(6.11)$ & -0.729 & $24.44(6.03)$ & $23.09(6.67)$ & $-1.344^{*}$ \\
\hline Premature & 0.13 & 0.09 & -0.047 & 0.10 & 0.06 & -0.041 \\
\hline Breastfed & 0.20 & 0.19 & -0.017 & 0.26 & 0.24 & -0.023 \\
\hline Other adults in the household & 0.17 & 0.14 & -0.027 & 0.22 & 0.13 & $-0.089^{\star}$ \\
\hline Precarious roofs or floor & 0.31 & 0.28 & -0.027 & 0.30 & 0.29 & -0.011 \\
\hline No sanitation in household & 0.25 & 0.22 & -0.029 & 0.21 & 0.23 & 0.024 \\
\hline Wealth index & $0.25(0.14)$ & $0.25(0.14)$ & 0.008 & $0.25(0.13)$ & $0.24(0.14)$ & -0.011 \\
\hline Government assistance & 0.64 & 0.68 & 0.032 & 0.63 & 0.71 & 0.085 \\
\hline Attended at least six workshop sessions & 0.84 & 0.86 & 0.019 & 0.82 & 0.80 & -0.016 \\
\hline
\end{tabular}


Table 1. (Continued.)

\begin{tabular}{|c|c|c|c|c|c|c|}
\hline & \multicolumn{3}{|c|}{ Sample with videos at baseline and follow-up } & \multicolumn{3}{|c|}{ Sample with videos at follow-up } \\
\hline & (1) & (2) & (3) & (4) & (5) & (6) \\
\hline Mother completed middle school & 0.28 & 0.3 & 0.028 & 0.31 & 0.32 & 0.004 \\
\hline Mother completed high school & 0.27 & 0.29 & 0.026 & 0.29 & 0.24 & -0.051 \\
\hline Father works full time & 0.8 & 0.83 & 0.033 & 0.79 & 0.81 & 0.017 \\
\hline Any negative shock past 12 months & 0.52 & 0.53 & 0.016 & 0.58 & 0.58 & 0.002 \\
\hline Discount rate & $0.07(0.08)$ & $0.09(0.09)$ & 0.02 & $0.08(0.09)$ & $0.08(0.09)$ & 0.01 \\
\hline Parental sense of competence (efficacy) & $4.13(0.74)$ & $4.18(0.71)$ & 0.05 & $4.12(0.70)$ & $4.10(0.77)$ & -0.02 \\
\hline
\end{tabular}

Notes: Columns (1)-(3) refer to the sample with videos at baseline and follow-up and Columns (4)-(6) refer to the sample only with videos in follow-up. Columns (1) and (4) show mean values for the variables in each row across subjects with ITT $=0$. Columns (2) and (5) show mean values for the characteristics in each row for subjects with ITT $=1$. Standard deviations are reported in parentheses for nondichotomous variables. Columns (3) and (6) show the differences in covariates at baseline by ITT status that are obtained by regressing the covariate on a dummy variable that takes the value of 1 if ITT $=1$ and of 0 if ITT $=0$. Due to missing values, the number of observations for each covariate may differ slightly from the $N$ in the last row. The difference is statistically significant at: ${ }^{\star \star \star} 1 \%,{ }^{\star \star} 5 \%,{ }^{\star} 10 \%$ 
Regarding behavioral biases, we use the parent's discount rate to capture present bias, the number of negative shocks faced by the family to measure cognitive fatigue, and a parental efficacy scale to capture negative identities. Specifically, we use Kirby et al.'s (1999) Monetary Choice Questionnaire (MCQ) to measure the discount rate. Because the number of observations for the MCQ at baseline was quite small $(\mathrm{N}=$ 115), and we did not expect treatment to affect the parameter, we work with the MCQ as measured at follow-up $(N=148) .{ }^{9}$ The negative shocks variable reflects the total number of the following events experienced by the family in the 12 months prior to the follow-up survey: divorce, separation, moving, income falls, debt, drug problems in the family, the death of a close friend or a family member, unemployment, job problems, or problems with the law. We use the measure at follow-up because we do not expect treatment to affect these events, and we seek to capture family stress or emotional fatigue during the time the intervention took place. Finally, we use the Johnston and Mash's (1989) version of the Parental Efficacy Subscale in the Parental Sense of Competence Scale (PSOC). ${ }^{10}$ In this case, we choose to work with the baseline measure because we do expect treatment to affect parental efficacy.

Column (3) in Table 1 checks for balance in family baseline characteristics across treated and control groups. Out of 22 characteristics, we only find a statistically significant difference at $5 \%$ or less in the mother's age: treated mothers are 2.6 years older than control mothers. At a $10 \%$ level of significance, we also find that treated families have, on average, a larger number of children. The fact that we only find a difference at a $5 \%$ level in 1 out of 22 tested features suggests that our sample is balanced.

The sample with videos at follow-up (but not necessarily at baseline) is quite similar in terms of family characteristics to the other sample. ${ }^{11}$ But unlike the former, it shows differential attrition: treated families are 15 percentage points less likely to be videotaped at follow-up than control families. ${ }^{12}$ This results in a slightly larger imbalance of baseline characteristics. At a 5\% significance or less, mothers in the treatment group are older than those in the control, and the child is less likely to be an only child. There are more differences at the $10 \%$ level, with children in the treatment

\footnotetext{
${ }^{9}$ The geometric mean of the MCQ discount rate $k$ in our sample $(\ln (0.08)=-2.53)$ is larger than that found in Phillips et al. (2020) for a sample of overweight adults aged 18-60, and in Kirby et al. (1999) for a sample of opioid-dependent patients (3.96). Our measure is within the upper quartile of the $k$ distribution in the cited articles.

${ }^{10}$ The average of the PSOC efficacy subscale in our sample is 4.13 , similar to the 4.16 found among Spanish families with children aged 0-5 (Alvarez et al., 2021), but below the average scale in other English-speaking samples, such as in Karp et al. (2015) (4.85).

${ }^{11}$ Some minor differences include being less likely to have premature babies, being more likely to breastfeed, having more children and more adults in the household, and being more likely to have a negative shock in the past 12 months.

${ }^{12} \mathrm{We}$ offered families the option of being videorecorded at the early childhood center or at home. Some centers were more generous than others in offering us physical space and operation hours to record the videos. Because randomization was conducted at the center level, any barriers to video recording imposed by a single center could substantially affect the balance. The observed imbalance is, in fact, largely explained by one of the centers assigned to treatment, which accounted for more than $10 \%$ of the treated families, and in which we were only able to video-record $8 \%$ of the dyads. In all the other centers, participation was at least $40 \%$.
} 
group being younger and living with a larger number of other children and adults in the household. While only 2 out of 22 covariates are unbalanced at normal levels of significance, because 5 covariates are unbalanced at a p-level of 0.10 , in the next section, we device some strategies to address the differential attrition.

\section{Descriptive statistics of language outcomes}

Table 2 describes the main language outcomes we assess in the analysis. We present outcomes for control group families at follow-up, both for the sample with videos at baseline and follow-up and for the sample with videos at follow-up but not necessarily at baseline. On average, there are 112 child vocalizations in a 10 -minute free play interaction between the child and the caregiver. This average is above the number of vocalizations found by Soderstrom and Wittebolle (2013) in a similar setting (they report 55 vocalizations on average). The total duration of vocalizations is $200 \mathrm{~s}$ in the first sample and 195 in the second one. Adults show around 110 vocalizations, with a total duration of 146 sconds in the first sample and 158 in the second one. These counts are similar to those found by Hurtado et al. (2008) in a similar context of 10 minutes of organized playtime. There are around 90 conversational turns defined by a threshold of 0.3 seconds between vocalization off- and onset. Between $55 \%$ and $60 \%$ of the time, adults respond to children's vocalizations in less than $2 \mathrm{sec}-$ onds. The average frequency of the adult pitch is around 5.5 Equivalent Rectangular Bandwidths (ERB), and its range (the maximum frequency minus the minimum one) is around $2.4 \mathrm{ERB}$.

We also assess correlations across language outcomes (see Table A1). Children's count and duration of vocalizations are strongly associated with each other $(r=0.64$; $\mathrm{p}<0.01)$ as with conversational turns $(r=0.52 ; \mathrm{p}<0.01$ and $r=0.46 ; \mathrm{p}<0.01$, respectively). Adult count and duration of vocalizations show also a strong positive bivariate correlation, and both are associated with conversational turns and response ratio. Interestingly, while the count of adult vocalizations is positively, although not too strongly, associated with the count of child vocalizations $(r=0.18 ; \mathrm{p}<0.01)$, the duration of adult vocalizations is negatively associated with the duration of child vocalizations $(r=-0.19 ; \mathrm{p}<0.05)$, suggesting a possible crowding-out effect given the proposed fixed time activity. Finally, adult pitch range is positively correlated with count $(r=$ $0.24 ; \mathrm{p}<0.01)$ and duration $(r=0.42 ; \mathrm{p}<0.01)$ of adult vocalizations, but it is negatively correlated with the count of child vocalizations $(r=-0.18 ; \mathrm{p}<0.05)$. Adult pitch average is negatively correlated with the duration of child vocalizations $(r=-0.37 ; \mathrm{p}<0.01)$ and uncorrelated with adult vocalization count and duration.

\section{Estimation approach}

We run ordinary least squares regressions of each language outcome on an indicator of having been randomly assigned to receive messages. The coefficient of the latter indicator provides us with the Intention-to-Treat (ITT) effect, or the effect of having been randomly assigned to receive messages, on language outcomes. In our core analysis, we estimate ITT effects using the sample with videos both at baseline and at follow-up. We then run robustness analyses on the sample with videos at follow-up (but not 
Table 2. Description of language outcomes for control families at follow-up $(N=98)$

\begin{tabular}{|c|c|c|c|c|c|c|}
\hline & \multicolumn{2}{|c|}{$\begin{array}{l}\text { Sample with } \\
\text { videos at } \\
\text { baseline and } \\
\text { follow-up }\end{array}$} & \multicolumn{4}{|c|}{ Sample with videos at follow-up } \\
\hline & Mean & SD & Mean & SD & Minimum & Maximum \\
\hline & $(1)$ & $(2)$ & (3) & (4) & (5) & (6) \\
\hline Count of child vocalizations & 111.9 & 44.0 & 112.3 & 45.9 & 11 & 196 \\
\hline Duration of child vocalizations (s) & 200.4 & 123.5 & 195.4 & 120.6 & 7 & 554 \\
\hline Count of adult vocalizations & 108.2 & 51.6 & 111.0 & 51.7 & 16 & 236 \\
\hline Duration of adult vocalizations & 145.6 & 99.0 & 158.4 & 105.9 & 10 & 400 \\
\hline Total vocalization duration & 346.0 & 150.9 & 353.8 & 156.4 & 26 & 701 \\
\hline Turns (0.3 s) & 88.9 & 53.1 & 92.8 & 54.5 & 2 & 206 \\
\hline Adult response ratio & 0.6 & 0.2 & 0.6 & 0.2 & 0 & 1 \\
\hline Adult pitch average & 5.5 & 0.8 & 5.6 & 0.7 & 3 & 7 \\
\hline Adult pitch range & 2.4 & 0.8 & 2.5 & 0.8 & 1 & 5 \\
\hline
\end{tabular}

necessarily at baseline). While the first sample is smaller, it is more balanced across treatment and control subjects and allows us to estimate standard errors with more precision by accounting for the outcome at baseline. We also explore spillover effects by including in our estimations an indicator if the family was assigned to the control group but belonged to a center that was randomized into treatment. Note, however, that due to the small number of videos observed in this subsample, we do not expect estimates on spillovers to be precise and do not emphasize this feature in the analysis.

To improve precision and address potential sample selection due to attrition, in our core specification, we adjust for a set of covariates including (1) the value of the outcome at baseline; ${ }^{13}(2)$ the variable used to stratify the randomization at the CAIF center level (a dummy equal to one if the average level of education of mothers participating in Crianza Positiva at the center was at least middle school); (3) covariates that were unbalanced after attrition at a significant level of $10 \%$ or less (the mother's age and the number of other children in the household); and (4) other covariates that could help improve the precision of the estimation, such as the child's age and gender, mother's education, whether the child lived with both biological parents, father's working status, and the number of months that elapsed between the date when the intervention began and the final assessment. For statistically significant outcomes, we report an adjusted p-value of the ITT coefficient after accounting for the clustering of observations around centers using wild bootstrapping (Cameron et al., 2008). We also adjust p-values for multiple hypotheses testing using the Romano Wolf algorithm (Clarke et al., 2020).

\footnotetext{
${ }^{13}$ To maximize sample size, we consider observations that had a recording in at least one of the two preintervention assessments (August 2017 or November-December 2017). We control for dummy variables that account for the timing of this assessment.
} 
We check for robustness by adjusting for different combinations of covariates in the main sample. In addition, we address the differential probability of being assigned to treatment and control arms by using inverse probability weighting: we estimate the probability that the family belongs to the treatment, conditional on the observed covariates at baseline, and then weight treated observations by the inverse of such probability, and control observations by the inverse of 1 minus such probability. We also run the analysis in the full sample with videos at follow-up, without adjusting for baseline outcomes.

\section{Results \\ Main specification}

Our core specification estimates ITT effects for the sample with videos both at baseline and at follow-up. Table 3 reports the effects of the intervention on the different language outcomes: measures of count and duration of vocalizations (in columns 1-5) and measures of conversational quality (in columns 6-9). At a $10 \%$ level of statistical significance, we find evidence that the intervention decreased the total duration of child vocalizations and increased the total duration of adult vocalizations. The estimates on the ITT indicator are -45 seconds per vocalization for the child, compared with an average duration for control children of 200 seconds (-23\%), and 29 s for adults, compared with an average of 146 seconds for control subjects (20\%). The finding that adults speak more is in line with our hypotheses, but not the finding that children vocalize less. We find no statistically significant effects over the summation of child and adult vocalizations (total vocalization duration), suggesting that parental vocalizations are crowding out child vocalizations. There is no evidence of effects on the count of child or adult vocalizations. Once we account for clustering of observations around centers, the effect on the duration of adult vocalizations loses statistical significance at traditional levels. Also, none of the effects are robust to adjustment for multiple hypotheses testing.

Regarding outcomes that assess communication quality, the first outcomes analyzed, conversational turns, and parental responsiveness show no differences across treated and control subjects. Coefficients appear to be imprecisely estimated. On the other hand, we find a strong and positive effect on a measure of speech quality: the range of adult pitch. This estimate is 0.4 higher for parents in the intervention group, $18 \%$ above the frequency range observed for control parents (2.4 ERB). The effect remains statistically significant at $\mathrm{p}<0.10$ after clustering standard errors around centers using wild bootstrapping techniques and at $p<0.05$ after adjusting p-values for multiple hypotheses testing. We also find that the intervention had a positive and statistically significant effect at the $10 \%$ level on the range of adult pitch in the spillover sample, robust to wild bootstrapping but not to multiple hypotheses testing. These effects support our hypothesis that the intervention contributed to improve the quality of language input.

\section{Robustness}

Table 4 shows ITT effects conditional on different sets of covariates. We include outcomes for which the effect was statistically significant in Table 3. Specification 1 
Table 3. ITT effects of CP messages on language outcomes

\begin{tabular}{|c|c|c|c|c|c|c|c|c|c|}
\hline & \multicolumn{5}{|c|}{ Count and duration of vocalizations } & \multicolumn{4}{|c|}{ Conversational quality } \\
\hline & $\begin{array}{c}\text { Count of } \\
\text { child } \\
\text { vocalizations }\end{array}$ & $\begin{array}{l}\text { Duration of } \\
\text { child } \\
\text { vocalizations } \\
\text { (s) }\end{array}$ & $\begin{array}{c}\text { Count of } \\
\text { adult } \\
\text { vocalizations }\end{array}$ & $\begin{array}{l}\text { Duration of } \\
\text { adult } \\
\text { vocalizations } \\
\text { (s) }\end{array}$ & $\begin{array}{c}\text { Total } \\
\text { vocalization } \\
\text { duration (s) }\end{array}$ & $\begin{array}{l}\text { Number of } \\
\text { turns } \\
\text { (threshold } \\
\text { of } 0.3 \mathrm{~s} \text { ) }\end{array}$ & $\begin{array}{l}\text { Adult } \\
\text { response } \\
\text { ratio }\end{array}$ & $\begin{array}{c}\text { Adult } \\
\text { pitch } \\
\text { average }\end{array}$ & $\begin{array}{l}\text { Adult } \\
\text { pitch } \\
\text { range }\end{array}$ \\
\hline & $(1)$ & $(2)$ & (3) & (4) & (5) & (6) & (7) & (8) & (9) \\
\hline ITT coefficient & -10.266 & $-44.668^{\star}$ & 9.218 & $28.993^{\star}$ & -16.555 & -3.011 & 0.028 & 0.162 & $0.424^{\star \star \star}$ \\
\hline ITT SE & $(8.060)$ & $(22.819)$ & $(8.261)$ & $(17.265)$ & $(27.502)$ & $(9.451)$ & $(0.038)$ & $(0.133)$ & $(0.147)$ \\
\hline Wild bootstrapping $\mathrm{p}$-value & & {$[0.095]$} & & {$[0.289]$} & & & & & {$[0.066]$} \\
\hline Romano Wolf mht $p$-value & & {$[0.193]$} & & {$[0.269]$} & & & & & {$[0.016]$} \\
\hline Spillover coefficient & -12.880 & -35.642 & 25.764 & 50.041 & 18.079 & 6.863 & 0.095 & 0.035 & $0.405^{\star}$ \\
\hline Spillover SE & $(12.015)$ & $(38.433)$ & $(15.655)$ & $(33.307)$ & $(42.005)$ & $(15.320)$ & $(0.064)$ & $(0.214)$ & $(0.235)$ \\
\hline Wild bootstrapping $\mathrm{p}$-value & & & & & & & & & {$[0.077]$} \\
\hline Romano Wolf mht $p$-value & & & & & & & & & {$[0.308]$} \\
\hline$N$ & 159 & 157 & 159 & 159 & 157 & 159 & 157 & 158 & 158 \\
\hline Outcome mean ITT =0 & 111.88 & 200.39 & 108.20 & 145.62 & 346.02 & 88.86 & 0.55 & 5.52 & 2.42 \\
\hline Outcome SD ITT = 0 & 43.96 & 123.53 & 51.61 & 99.04 & 150.87 & 53.06 & 0.21 & 0.75 & 0.79 \\
\hline
\end{tabular}

Notes: ${ }^{*} p<0.1,{ }^{* \star *} p<0.01$. The table shows the effects of randomization into treatment (ITT) or into the spillover sample on quantitative language outcomes after adjusting for the following set of covariates: randomization strata, outcome at baseline, mother's education, mother's age, child's gender, child's age in months when the intervention began, the number of months that elapsed between the final assessment and the date when the intervention began, the number of people in the household, single child, whether the father worked full time at baseline, and indicators for the timing when the family was videotaped at baseline (in August 2017, in November-December 2017, or both). When there are two baseline measures, we use the average. Robust standard errors are reported in parentheses. For significant outcomes, we report in squared brackets the p-values after adjusting standard errors for clustering of observations around centers using wild bootstrapping. We also report p-values after adjusting for multiple hypotheses testing (mht) using the Romano Wolf algorithm and considering two families of outcomes: count and duration of vocalizations, and conversational quality. 
Table 4. Robustness of ITT effects to different sets of covariates

\begin{tabular}{lccc}
\hline & $\begin{array}{c}\text { Duration of child } \\
\text { vocalizations }\end{array}$ & $\begin{array}{c}\text { Duration of adult } \\
\text { vocalizations }\end{array}$ & $\begin{array}{c}\text { Adult pitch } \\
\text { range }\end{array}$ \\
Outcomes & $(1)$ & $(2)$ & $(3)$ \\
\hline Alternative specifications & & & \\
\hline (1) Covariates: average of SES and baseline outcome between baseline 0 and baseline $1(N=159)$ \\
\hline ITT coefficient & $-44.668^{*}$ & $28.993^{*}$ & $0.424^{\star \star *}$ \\
\hline ITT SE & $(22.819)$ & $(17.265)$ & $(0.147)$ \\
\hline Wild bootstrapping p-value & {$[0.095]$} & {$[0.289]$} & {$[0.066]$} \\
\hline
\end{tabular}

(2) Covariates: SES and baseline outcomes at baseline 1 (use baseline 0 when baseline 1 missing) $(N=157)$

\begin{tabular}{lccc}
\hline ITT coefficient & $-44.079^{\star}$ & $29.239^{\star}$ & $0.408^{\star \star \star}$ \\
\hline ITT SE & $(22.539)$ & $(17.018)$ & $(0.149)$ \\
\hline Wild bootstrapping p-value & {$[0.119]$} & {$[0.280]$} & {$[0.080]$} \\
\hline
\end{tabular}

(3) Covariates: SES and baseline outcomes at baseline 0 (use baseline 1 when baseline 0 missing) $(N=157)$

\begin{tabular}{lccc}
\hline ITT coefficient & $-43.399^{*}$ & 27.863 & $0.428^{\star \star *}$ \\
\hline ITT SE & $(22.81)$ & $(17.257)$ & $(0.143)$ \\
\hline Wild bootstrapping p-value & {$[1.261]$} & & {$[0.070]$} \\
\hline
\end{tabular}

(4) Covariates: average baseline outcome between baseline 0 and 1 ; no adjustment for SES $(N=174)$

\begin{tabular}{lccc}
\hline ITT coefficient & -26.124 & $30.392^{\star}$ & $0.389^{\star \star \star}$ \\
\hline ITT SE & $(19.767)$ & $(16.06)$ & $(0.133)$ \\
\hline Wild bootstrapping p-value & & {$[0.282]$} & {$[0.054]$} \\
\hline (5) Same as 1$)+$ inverse probability weighting $(N=145)$ & & \\
\hline ITT coefficient & -27.290 & $33.306^{\star}$ & $0.412^{\star \star \star}$ \\
\hline ITT SE & $(23.248)$ & $(17.030)$ & $(0.143)$ \\
\hline Wild bootstrapping p-value & & {$[0.240]$} & {$[0.054]$} \\
\hline
\end{tabular}

Notes: ${ }^{\star} p<0.1 ;{ }^{\star \star \star} p<0.01$. The table shows the effects of randomization into treatment (ITT) on language outcomes after adjusting for different sets of covariates. The columns indicate different outcomes and rows specifications with different sets of covariates in the regressions. For each outcome/specification combination, we show the ITT coefficient from the regression, its robust standard error in parentheses, and in square brackets the $p$-values after clustering standard errors around centers using wild bootstrapping (WB p). Specification 1 shows ITT estimates after adjusting for sociodemographic characteristics (SES) and the average of the outcome measured at the two baseline surveys. Specification 2 shows ITT effects after adjusting for SES and the outcome variable at the last baseline survey if available or at the first baseline survey otherwise. Specification 3 shows ITT results adjusting for SES and the outcome at the first baseline survey or at the second one otherwise. Specification 4 shows ITT effects adjusting for the average of the outcome at the two baseline surveys, but without adjustment for SES. Specification 5 is similar to 1, but weights observation for the inverse probability of having been assigned to treatment.

replicates results in Table 3 (same coefficients as in columns (2), (4), and (9)). Specification 2 shows ITT effects after adjusting for sociodemographic status and the outcome variable at the last baseline survey, if available, or at the first baseline survey otherwise. The third specification shows ITT results adjusting for SES and 
the outcome at the first baseline survey, or at the second baseline survey otherwise. Specification 4 shows ITT effects when adjusting for the average of the outcome at the two baseline surveys only (no adjustment for SES). The final specification weights treatment and control observations for the inverse of the estimated propensity score of being in each group. We report wild bootstrapping p-values in square brackets. The results are very robust when assessing the effect of treatment on adult pitch range. Coefficients on the duration of child and adult vocalizations, on the other hand, are more sensitive to alternative specifications; and as in Table 3, first panel, most of the estimates lose statistical significance after adjusting standard errors for clustering.

In Table A2 we show the results of estimating the Treatment on the Treated (TOT), rather than ITT, effects. We use two-stage least-square estimation techniques and instrument the probability of having received at least one message with the indicator of random assignment to treatment. The results are very similar to those in Table 3. Exposure to the messages decreases the duration of child vocalizations by 47 seconds (wild bootstrapping p-value $=0.09$ ) and increases the duration of adult vocalizations by 40 seconds, although this effect becomes marginally insignificant once we cluster standard errors around centers. Receiving parenting messages continues to show a strong positive effect on adult pitch range (0.50 ERB), which remains statistically significant at $5 \%$ after clustering standard errors.

Next, we estimate ITT results analyzing the video's last 300 seconds rather than the full video (which theoretically should have an extension of 600 seconds). We do so for two reasons: (1) to measure outcomes in a similar timeframe for all observations and (2) because we expect mother and child to be more relaxed and less influenced by socially desirable norms in the second half of the video. The results continue to show a positive effect of the intervention on the adult pitch range - of $0.43 \mathrm{ERB}$ - and some evidence of an increase in the duration of adult vocalizations, which marginally loses statistical significance after adjusting standard errors for clustering (see Table A3).

In Table A4, we show results when running the ITT analysis for the full sample of families with a video recording at follow-up (regardless of having or not a video at baseline). Again, we identify a positive ITT effect on the adult pitch range and a negative effect on the duration of child vocalizations, but the magnitudes are smaller than in the core specification and lose statistical significance after clustering standard errors around centers.

\section{Mechanisms}

We explore mechanisms in two ways. First, we investigate whether exposure to the message content led parents to increase their involvement in activities associated with language development. As mentioned before, $17 \%$ of messages encouraged parents to engage in language-enhancing activities such as holding conversations with the child, asking open questions, describing objects, places and activities, reading to the child, or singing and listening to songs together. Furthermore, other messages were oriented toward strengthening parental-child interactions through the development of sensitivity and responsiveness, key features for good communication and language development.

In a post-treatment survey (administered between one and three months after the messaging intervention finished), we asked parents for their frequency of involvement 
in several activities with the child, including singing songs, reading, telling stories, and naming, telling, or drawing things. Each measure ranged from 1 to 7 , where 1 was never in the week and 7 was every day or nearly every day. We standardized each outcome dividing it by the standard deviation of the outcome in the control group. In addition, we constructed an aggregate index of parental involvement in literacy activities using the first component of a principal component analysis on the six parental involvement outcomes. This component explained 53\% of the overall variability in the outcomes and was also standardized. We regressed all standardized outcomes on the ITT indicator, adjusting for the same set of covariates as in our core specification. ${ }^{14}$ The results are reported in Table 5. Being assigned to treatment increased the frequency of reading books, telling stories, and naming, telling, or drawing things to the child by 0.30 , 0.27 , and 0.44 standard deviations, respectively. The overall effect on the aggregate index is 0.37 standard deviations. All effects are robust to wild bootstrapping.

We also investigate whether these parental involvement outcomes correlate with the pitch range and the duration of adult vocalization at follow-up, the two parental language outcomes for which we find a positive effect of the intervention. We find a correlation of $r=0.13(\mathrm{p}<0.1)$ between telling stories to the child and the adult pitch range. We do not find a statistically significant association between the measures of parental engagement and the adult vocalization duration, but do find a significant correlation between the aggregate index of parental engagement and the total duration of vocalizations $(r=0.14 ; \mathrm{p}<0.1)$.

Next, we explore whether ITT effects are heterogeneous across parents with different degrees of behavioral biases. Recall that the messages aimed at addressing behavioral barriers such as present bias, cognitive fatigue, and negative identities. The first message of the week presented information and reminded parents on the importance of a specific parenting practice (making future benefits more salient); the second one addressed cognitive fatigue and inattention by proposing simple and concrete activities to do during the week; and the third one targeted parental identities, via messages of encouragement and reflection. If the messages work by circumventing these behavioral biases, we would expect parents with stronger biases to react more to the treatment. As shown in Table 1, we measured these dimensions by using parents' discount rate (present bias), negative shocks faced by the family (cognitive fatigue), and parents' sense of competence (parental identity). We expect the treatment to have stronger impacts among parents with higher discount rates, households with more negative shocks, and parents with a lower sense of competence. For each language outcome that was affected by the intervention, we run a regression that adds to the core specification a main effect for a behavioral barrier and an interaction between this barrier and the ITT variable (see Table 6). Rather than using the measures for discount rates, negative shocks, and parental efficacy displayed in Table 1, we work with dichotomous indicators of these variables being above (discount rate, negative shocks) or below (parental efficacy) the mean. We find that parents with high discount rates or low efficacy are more likely to show increases in the pitch range after treatment at $\mathrm{p}<0.05$ and $\mathrm{p}<0.1$, respectively. Both effects are robust to

\footnotetext{
${ }^{14}$ This includes strata indicators, an indicator of being a part of the spillover sample, outcomes at baseline, and a set of covariates capturing family SES.
} 
Table 5. Effects of CP messages on parental frequency of involvement in literacy activities

\begin{tabular}{|c|c|c|c|c|c|c|}
\hline & $\begin{array}{l}\text { I sing songs } \\
\text { to my child } \\
\text { (1) }\end{array}$ & $\begin{array}{l}\text { My child and I } \\
\text { sing songs } \\
\text { together } \\
\text { (2) }\end{array}$ & $\begin{array}{l}\text { I read books to my } \\
\text { child or we look at } \\
\text { images } \\
\text { (3) }\end{array}$ & $\begin{array}{l}\text { I tell stories } \\
\text { to my child } \\
\text { (4) }\end{array}$ & $\begin{array}{l}\text { I name, tell, or } \\
\text { draw things to my } \\
\text { child } \\
\text { (5) }\end{array}$ & $\begin{array}{l}\text { Index of parental } \\
\text { involvement in literacy } \\
\text { activities } \\
\text { (6) }\end{array}$ \\
\hline $\begin{array}{l}\text { ITT standardized } \\
\text { coefficient }(d)\end{array}$ & 0.117 & 0.172 & $0.295^{\star *}$ & $0.271^{\star}$ & $0.437^{\star \star \star}$ & $0.374^{\star \star \star}$ \\
\hline ITT SE & $(0.152)$ & $(0.158)$ & $(0.143)$ & $(0.147)$ & $(0.158)$ & $(0.136)$ \\
\hline $\begin{array}{l}\text { Wild bootstrapping } \\
\text { p-value }\end{array}$ & & & {$[0.077]$} & [0.047] & {$[0.007]$} & [0.012] \\
\hline$N$ & 145 & 145 & 145 & 141 & 152 & 133 \\
\hline
\end{tabular}

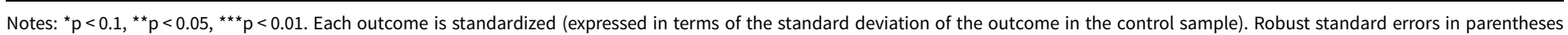
and $\mathrm{p}$-value after clustering standard errors with wild bootstrapping in squared brackets (only for significant outcomes). Regressions adjust for strata, an indicator of nontreated families within

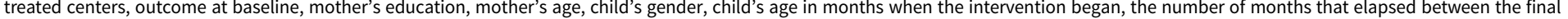
assessment and the date when the intervention began, the number of people in the household, single child, and whether the father worked full time at baseline. The sample includes observations with videos at baseline and follow-up. 
Table 6. Heterogeneity of ITT effects by behavioral barrier

\begin{tabular}{|c|c|c|c|}
\hline & $\begin{array}{l}\text { Duration of child } \\
\text { vocalizations } \\
\text { (1) }\end{array}$ & $\begin{array}{l}\text { Duration of adult } \\
\text { vocalizations } \\
\text { (2) }\end{array}$ & $\begin{array}{l}\text { Adult pitch } \\
\text { range } \\
\text { (3) }\end{array}$ \\
\hline \multicolumn{4}{|l|}{ Present bias } \\
\hline \multirow[t]{2}{*}{ ITT } & $-59.197^{\star}$ & 17.052 & 0.170 \\
\hline & $(31.302)$ & $(22.734)$ & $(0.164)$ \\
\hline \multirow[t]{2}{*}{ High discount rate } & 20.612 & -14.791 & -0.065 \\
\hline & $(32.754)$ & $(25.298)$ & $(0.209)$ \\
\hline \multirow{3}{*}{$\begin{array}{l}\mathrm{ITT}^{\star} \text { high discount } \\
\text { rate }\end{array}$} & 9.249 & 33.968 & $0.583^{\star \star}$ \\
\hline & $(46.708)$ & $(36.437)$ & $(0.267)$ \\
\hline & & & {$[0.080]$} \\
\hline$N$ & 147 & 149 & 148 \\
\hline \multicolumn{4}{|l|}{ Cognitive fatigue } \\
\hline \multirow[t]{2}{*}{ ITT } & -35.804 & 8.938 & $0.354^{\star \star}$ \\
\hline & $(28.414)$ & $(20.531)$ & $(0.162)$ \\
\hline \multirow[t]{2}{*}{ Negative shocks } & 19.197 & 12.702 & 0.200 \\
\hline & $(28.546)$ & $(22.526)$ & $(0.201)$ \\
\hline \multirow{2}{*}{$\begin{array}{l}\text { ITT* negative } \\
\text { shocks }\end{array}$} & -21.237 & 44.682 & 0.198 \\
\hline & $(39.641)$ & $(34.462)$ & $(0.276)$ \\
\hline$N$ & 155 & 157 & 156 \\
\hline \multicolumn{4}{|l|}{ Negative identities } \\
\hline \multirow[t]{2}{*}{ ITT } & $-52.683^{\star}$ & 36.753 & 0.144 \\
\hline & $(31.292)$ & $(24.875)$ & $(0.186)$ \\
\hline \multirow{2}{*}{$\begin{array}{l}\text { Low parental } \\
\text { efficacy }\end{array}$} & -2.959 & -4.829 & -0.273 \\
\hline & $(30.961)$ & $(24.468)$ & $(0.188)$ \\
\hline \multirow{3}{*}{$\begin{array}{l}\text { ITT*low parental } \\
\text { efficacy }\end{array}$} & 54.186 & -26.325 & $0.474^{\star}$ \\
\hline & $(44.706)$ & $(36.614)$ & $(0.245)$ \\
\hline & & & [0.058] \\
\hline$N$ & 140 & 142 & 141 \\
\hline
\end{tabular}

Notes: ${ }^{\star} p<0.1 ;{ }^{\star \star} p<0.05$. Robust standard errors in parentheses. When the interaction of interest is statistically significant, we report in squared brackets $p$-values after adjusting for the clustering of observations around centers using wild bootstrapping. The estimation sample includes observations that have a video in baseline and follow-up. Each pair of rows denotes a specific model in which the ITT is interacted with a behavioral barrier measured at baseline. The first two rows correspond to a high present bias, proxied with a discount rate above the mean. The next couple of rows correspond to cognitive fatigue. The variable that measures the latter behavioral barrier is an indicator that takes the value of 1 if the family was exposed to 2 or more negative shocks in the previous 12 months to the survey. The last two rows correspond to negative identities. The variable that measures the latter behavioral barrier is an indicator that takes the value of 1 if the parental efficacy at baseline is less or equal than the mean. Each column denotes a different outcome. For each outcome, we show the coefficient and standard error for the ITT main effect, and the coefficient and standard error for the interaction between ITT and the behavioral barrier is analyzed. The estimations control for the main effect of the behavioral barrier analyzed, an indicator of whether the subject was randomized to control within treated CAIF centers (the 'spillover' sample), for randomization strata, SES, and outcomes at baseline. 
wild-bootstrapped standard errors and have the expected sign. Impatient parents are more likely to react to messages that remind them about the benefits of speaking and reading to the child, and of responding sensibly to the child's cues. Parents with a low sense of efficacy are more likely to react to messages of encouragement and support. The coefficient on the other interaction (ITT times parental cognitive fatigue) is also positive but statistically insignificant.

\section{Discussion and conclusions}

In this article, we assess the effects of the Crianza Positiva text and audio e-messaging program on caregiver-child language interaction patterns. The Crianza Positiva e-messaging program is a three-times-a-week, six-month-long intervention for families with children aged $0-2$ years aimed at improving parenting competences. Its design recognizes that parental biases, such as present bias, inattention and cognitive fatigue, and negative identities, may lead to suboptimal parenting practices and exploits behavioral tools such as reminders, suggestions of actions, and messages of encouragement to reinforce and sustain positive parenting practices.

Crianza Positiva messages address the parental-child interaction by reinforcing sensitive observation, response, caring, and stimulation. These features are key components of a high-quality communication between the child and the caregiver, and set the grounds for language development. In addition, several modules of the Crianza Positiva e-messaging program (almost one out of five of the messages) are aimed specifically at language stimulation, encouraging parents to engage in conversations with the child, ask open questions, describe objects, places, and activities, read books, tell stories, and sing to and with the child.

We evaluate the program using a randomized controlled trial in 24 early childhood centers in Uruguay. Families that had completed an eight-week workshop at the center were randomized into receiving or not receiving mobile messages. After the program, we videotaped 10-minute sessions of free play between the caregiver and the child and decoded language patterns using automated techniques. We find that the intervention was successful at influencing parental behavior: it increased both the duration and the quality of parental vocalizations, as captured by the pitch range. While the effect on the duration of parental vocalization was sensitive to alternative specifications, the effect on pitch range was very robust. Higher pitch has been associated with better infant-adult connection both in individual variation (e.g., a comparison of depressed and nondepressed mothers; Porritt et al., 2014) and in experimental settings (i.e., when the mother is shown a supposedly live video of her infant, but the infant can versus cannot actually hear the mother; Smith \& Trainor, 2008). Furthermore, studies show that speech conveying pitch variations (larger ranges of speaker intonations) also results in higher levels of attention, more word recall, and more recognition of information by the listener than those with homogenous pitch ranges across sentences (Rodero et al., 2017). Parentese speech, or speech characterized by higher pitch, slower tempo, and exaggerated intonation ranges, has been positively associated with early spoken word recognition and better acquisition of language by infants and has been shown to be preferred by children relative to standard speech (Liu et al., 2009; Singh et al., 2009; Ramírez-Esparza 
et al., 2017). In turn, better language outcomes are related to better long-run educational achievement and earnings (Gertler et al, 2014). These results are promising because pitch range is not a variable that parents can easily and consciously manipulate, and, thus, it could be less sensitive to desirability biases.

Consistent with parental language results, we find that the intervention also increased parental involvement in reading, telling stories, and describing things to the child, as self-reported by parents in a follow-up survey. Furthermore, we find a positive correlation between telling stories and parental pitch range, as well as between an aggregate index of parental engagement in literacy activities and the total duration of vocalizations. The findings above suggest that the effects on Parentese speech and adult vocalization duration may have been mediated by an impact of the intervention on parental engagement in language interactions with the child and language-stimulating activities. We also explore the heterogeneous effects of the intervention by parental characteristics that may be capturing behavioral biases. We find evidence that the messages were most effective on parents with high discount rates, supporting our hypothesis that reminders help present-oriented parents to make more salient the benefits of positive parental engagement with the child.

It is important to bear in mind that our study may be among the first to analyze short video recordings automatically in the context of large-scale studies (see Background and sections 'Language development in early childhood' to 'Measurement of language input and output'). We, therefore, first checked our proposed metrics in terms of their reliability against manual coding, as well as external validity (i.e., correlations with age, which is our best proxy for language development in this sample; see the section 'Outcomes'). Our results suggested low external validity of child measures, as only one of our measures correlated significantly with child age (a proxy for language development available in the same data set). The one measure that had some external validity was child vocalization duration, but this measure exhibited a decrease among the treated children as compared with those in the control group. Since we observe that there is basically a trade-off between adult speech duration and child speech duration, we attribute this negative result to a crowding-out effect by the caregiver in the context of a fixed 10-minute suggested activity and a more proactive parental role. We believe that the most reasonable interpretation for this effect is not a negative effect of the intervention on the child, but rather an unfortunate masking of potential effects on the child due to greater caregiver engagement. This suggests that our analyses, while sufficient to reveal changes in parental behavior, may not be ideal to measure potential positive effects on the child. Instead, perhaps qualitative analyses of children's vocalization content (such as an estimation of syntactic complexity and lexical diversity) may be more sensitive. Unfortunately, given the state of automatic speech recognition, it is not feasible to automatically generate transcriptions of these videos. Transcriptions for the 59 hours of data ${ }^{15}$ in the smaller sample would have required at least 1770 hours of human work, ${ }^{16}$ which was also not feasible.

\footnotetext{
${ }^{15} 178$ dyads $\times 2$ waves $\times 10$ minutes $=3560$ minutes or 59 hours.

$1659 \times 30=1770$. The transcription of 1 minute of adult vocalization content requires approximately 20 minutes, while the transcription of 1 minute child's vocalization content involves approximately 40 minutes.
} 
Our work contributes to a nascent literature exploiting text-based communication and behavioral economic insights to boost early childhood development. It is worth emphasizing that in our intervention, messages were sent after completing a workshop with the families, so compliance and message efficacy may have been larger due to this prior contact. Moreover, we also add value to the literature by rigorously measuring language outcomes, which are seldom measured in the field due to the methodological difficulties with caregiver reporting and child observation (Weber et al., 2017). Here, via the use of videos and automatic transcriptions, we are able to identify some interesting outcomes previously unexplored in the literature, such as parental intonation or pitch range. Our results demonstrate the large potential of these very low-cost interventions, based on mobile technology and on the understanding of behavioral biases, in changing and sustaining parental behavioral patterns that ultimately lead to improved child development.

Acknowledgments. We acknowledge financial support from Reaching U Foundation, the Inter-American Development Bank, and Agencia Nacional de Investigación e Innovación (ANII, Uruguay). A.C. acknowledges Agence Nationale de la Recherche (ANR-17-CE28-0007 LangAge, ANR-16-DATA-0004 ACLEW, ANR-14-CE30-0003 MechELex, ANR-17-EURE-0017) and the J. S. McDonnell Foundation. The RCT design for this project was registered in the AEA RCT registry with RCT ID number AEARCTR-0003585. The project was approved by the Institutional Ethics Review Board at Universidad Católica del Uruguay, resolution A 22-08-17. A.B. discloses her position as a board member of Reaching U Foundation, one of the funding agencies. F.L.B. and M.P.F. work for the IADB, another funding agency in the project.

Conflict of interest. There are no other conflicts of interest to disclose.

\section{References}

Aboud, F. E., D. R. Singla, M. I. Nahil and I. Borisova (2013), 'Effectiveness of a parenting program in Bangladesh to address early childhood health, growth and development', Social Science and Medicine, 97 (Special Issue: Critical Periods in Early Human Development, Guest Editors: Pia Rebello Britto, UNICEF, USA; Rafael Pérez-Escamilla, Yale University, USA): 250-258.

Ajzenman, N. and F. Lopez Boo (2019), Lessons from behavioral economics to improve treatment adherence in parenting programs: An application to SMS. IZA Discussion Paper No. 12808. Retrieved from: https:// www.iza.org/publications/dp/12808/lessons-from-behavioral-economics-to-improve-treatment-adherence-in-parenting-programs-an-application-to-sms.

Allen, S. E. and C. Dench (2015), 'Calculating mean length of utterance for Eastern Canadian Inuktitut', First Language, 35(4-5): 377-406.

Alvarez, M., S. Byrne and M. J. Rodrigo (2021), 'Social support dimensions predict parental outcomes in a Spanish early intervention program for positive parenting', Children and Youth Services Review, 121: 105823.

Baird, S., J. A. Bohren, C. McIntosh and B. Özler (2018), 'Optimal design of experiments in the presence of interference', Review of Economics and Statistics, 100(5): 844-860.

Bayley, N. (1969), Bayley Scales of Infant Development [Measurement instrument]. San Antonio, TX: The Psychological Corporation.

Bénabou, R. and J. Tirole (2002), 'Self-confidence and personal motivation', The Quarterly Journal of Economics, 117(3): 871-915.

Berlinski, S. and N. Schady (2015), 'More bang for the buck: Investing in early childhood development', in S. Berlinksy, and N. Schady (eds), The early years, New York: Palgrave Macmillan, 149-178.

Bloomfield, J., A. Balsa and A. Cid (2020), Using behavioral insights in early childhood interventions: The effects of Crianza Positiva e-messaging program on parental investment. Universidad de Montevideo. Working Paper. 
Bornstein, M. H., D. L. Putnick, L. R. Cote, O. M. Haynes and J. T. D. Suwalsky (2015), 'Mother-infant contingent vocalizations in 11 countries', Psychological Science, 26(8): 1272-1284.

Cameron, A. C., J. B. Gelbach and D. L. Miller (2008), 'Bootstrap-based improvements for inference with clustered errors', The Review of Economics and Statistics, 90(3): 414-427.

Clarke, D., J. P. Romano and M. Wolf (2020), 'The Romano-Wolf multiple-hypothesis correction in Stata', The Stata Journal, 20(4): 812-843.

Conti, G., S. Poupakis, M. Sandner and S. Kliem (2020), The effects of home visiting on mother-child interactions: evidence from a randomized trial using dynamic micro-level data. IZA DP No. 12937.

Cristia, A. (2013), 'Input to language: The phonetics and perception of infant-directed speech', Language and Linguistics Compass, 7(3): 157-170.

Dale, A. and A. Strauss (2009), 'Don't forget to vote: Text message reminders as a mobilization tool', American Journal of Political Science, 53(4): 787-804.

Doss, C., E. M. Fahle, S. Loeb and B. N. York (2019), 'More than just a nudge supporting kindergarten parents with differentiated and personalized text messages', Journal of Human Resources, 54(3): 567-603.

Fenson, L., P. S. Dale, J. S. Reznick, D. Thal, E. Bates, J. P. Hartung, S. Pethick and J. S. Reilly (1993), The MacArthur communicative development inventories: User's guide and technical manual. San Diego: Singular Publishing Group.

Fenson, L., P. S. Dale, J. S. Reznick, E. Bates, D. J. Thal and S. J. Pethick (1994), 'Variability in early communicative development', Monographs of the Society for Research in Child Development, 59(5): 1-173.

Ferjan Ramírez, N., S. R. Lytle, M. Fish and P. K. Kuhl (2019), 'Parent coaching at 6 and 10 months improves language outcomes at 14 months: A randomized controlled trial', Developmental Science, 22 (3): e12762.

Ferjan Ramírez, N., S. R. Lytle and P. K. Kuhl (2020), 'Parent coaching increases conversational turns and advances infant language development', Proceedings of the National Academy of Sciences, 117(7): 34843491.

Fernald, A. and P. Kuhl (1987), 'Acoustic determinants of infant preference for motherese speech', Infant Behavior and Development, 10(3): 279-293.

Fernald, L., P. Kariger, P. Engle and A. Raikes (2009), Examining child development in low-income countries: a toolkit for the assessment of children in the first five years of life. Washington, DC: The World Bank.

Fernald, A., V. A. Marchman and A. Weisleder (2013), 'SES differences in language processing skill and vocabulary are evident at 18 months', Developmental Science, 16(2): 234-248.

Frankenburg, W. K., J. Dodds, P. Archer, H. Shapiro and B. Bresnick (1992), 'The Denver II: A Major Revision and Restandardization of the Denver Developmental Screening Test', Pediatrics, 89(1): 91-97.

Gennetian, L., M. Darling and J. L. Aber (2016), 'Behavioral economics and developmental science: A new framework to support early childhood interventions', Journal of Applied Research on Children, 7(2): 2.

Gertler, P., J. Heckman, R. Pinto, A. Zanolini, C. Vermeerch, S. Walker, S. M. Chang and S. Grantham-McGregor (2014), 'Labor market returns to an early childhood stimulation intervention in Jamaica', Science, 344(6187): 998-1001.

Gilkerson, J., J. A. Richards, S. F. Warren, J. K. Montgomery, C. R. Greenwood, D. Kimbrough Oller and T. D. Paul (2017), 'Mapping the early language environment using all-day recordings and automated analysis', American Journal of Speech-language Pathology, 26(2): 248-265.

Gurol-Urganci, I., T. de Jongh, V. Vodopivec-Jamsek, R. Atun and J. Car (2013), 'Mobile phone messaging reminders for attendance at healthcare appointments', Cochrane Database of Systematic Reviews, 2012 Jul 11(7): CD007458.

Hart, B. and T. R. Risley (1995), Meaningful differences in the everyday experience of young American children. Baltimore, MD: Paul H. Brookers Publishing.

Hurtado, N., V. A. Marchman and A. Fernald (2008), 'Does input influence uptake? Links between maternal talk, processing speed and vocabulary size in Spanish-learning children', Developmental Science, 11 (6): 31-39.

Hurwitz, L. B., A. R. Lauricella, A. Hanson, A. Raden and E. Wartella (2015), 'Supporting Head Start parents: impact of a text message intervention on parent-child activity engagement', Early Child Development and Care, 185(9): 1373-1389.

Johnston, C. and E. J. Mash (1989), 'A measure of parenting satisfaction and efficacy', Journal of Clinical Child Psychology, 18(2): 167-175. 
Karp, S. M., M. Lutenbacher and K. A. Wallston (2015), 'Evaluation of the parenting sense of competence scale in mothers of infants', Journal of Child and Family Studies, 24(11): 3474-3481.

Kirby, K. N., N. M. Petry and W. K. Bickel (1999), 'Heroin addicts have higher discount rates for delayed rewards than non-drug-using controls', Journal of Experimental Psychology: General, 128(1): 78-87.

Lavechin, M., M. de Seyssel, L. Gautheron, E. Dupoux and A. Cristia (2021), Reverse-engineering language acquisition with child-centered long-form recordings. https://doi.org/10.31234/osf.io/pt9xq.

Law, J., R. Rush, I. Schoon and S. Parsons (2009), 'Modeling developmental language difficulties from school entry into adulthood: literacy, mental health, and employment outcomes', The Journal of Speech, Language, and Hearing Research, 52(6): 1401-1416.

Le Franc, A., E. Riebling, J. Karadayi, Y. Wang, C. Scaff, F. Metze and A. Cristia (2018), The ACLEW DiViMe: An Easy-to-use Diarization Tool. In INTERSPEECH Conference Proceedings (pp. 1383-1387).

Leung, C. Y. Y., M. W. Hernandez and D. L. Suskind (2020), 'Enriching home language environment among families from low-SES backgrounds: A randomized controlled trial of a home visiting curriculum', Early Childhood Research Quaterly, 50: 24-35.

Liu, H. M., F. M. Tsao and P. K. Kuhl (2009), 'Age related changes in acoustic modifications of Mandarin maternal speech to preverbal infants and five-year-old children: A longitudinal study', Journal of Child Language, 36: 909-922.

Lopez Boo, F., M. Cubides Mateus, R. Sorio, G. Garibotto and C. Berón (2018), Measuring the quality of the home environment of young children in Uruguay: socioeconomic gradients in the home inventory. Inter-American Development Bank Technical Notes. IDB-TN-1550.

Love, J. M., E. E. Kisker, C. Ross, H. Raikes, J. Constantine, K. Boller and A. S. Fuligni (2005), 'The effectiveness of early head start for 3-year-old children and their parents: Lessons for policy and programs', Developmental Psychology, 41(6): 885.

Mani, A., S. Mullainathan, E. Shafir and J. Zhao (2013), 'Poverty impedes cognitive function', Science, 341 (6149): 976-980.

Mayer, S. E., A. Kalil, P. Oreopoulos and S. Gallegos (2018), 'Using behavioral insights to increase parental engagement: The parents and children together intervention', Journal of Human Resources, 54(4): 900925.

McGillion, M., J. M. Pine, J. S. Herbert and D. Matthews (2017), 'A randomized controlled trial to test the effect of promoting caregiver contingent talk on language development in infants from diverse socioeconomic status backgrounds', Journal of Child Psychology and Psychiatry, 58(10): 1122-1131.

Mendive, S., M. Mascareño Lara, D. Aldoney, J. C. Pérez and J. P. Pezoa (2020), 'Home language and literacy environments and early literacy trajectories of low-socioeconomic status Chilean children', Child Development, 91(6): 2042-2062.

Meuwissen, A., A. Giovanelli, M. Labella and A. Susman-Stillman (2017), Text2Learn: An early literacy texting intervention by community organizations.

Neumann, C. (2020), Avutils. Retrieved from: https:/github.com/gobbios/avutils.

NICHD (2000), 'The relation of child care to cognitive and language development', Child Development, 71 (4): 960-980.

Olds, D. L., H. Kitzman, R. Cole, J. Robinson, K. Sidora, D. W. Luckey and J. Holmberg (2004), 'Effects of nurse home-visiting on maternal life course and child development: age 6 follow-up results of a randomized trial', Pediatrics, 114(6): 1550-1559.

Phillips, C. B., J. C. Hurley, S. S. Angadi, M. Todd, V. Berardi, M. F. Hovell and M. A. Adams (2020), 'Delay discount rate moderates a physical activity intervention testing immediate rewards', Behavioral Medicine, 46(2): 142-152.

Porritt, L. L., M. C. Zinser, J. A. Bachorowski and P. S. Kaplan (2014), 'Depression diagnoses and fundamental frequency-based acoustic cues in maternal infant-directed speech', Language Learning and Development, 10(1): 51-67.

Ramírez-Esparza, N., A. García-Sierra and P. K. Kuhl (2017), 'Look who's talking NOW! Parentese speech, social context, and language development across time', Frontiers in Psychology, 8: 1008.

Rodero, E., R. F. Potter and P. Prieto (2017), 'Pitch range variations improve cognitive processing of audio messages', Human Communication Research, 43(3): 397-413.

Rodriguez, M. L., K. Dumont, S. D. Mitchell-Herzfeld, N. J. Walden and R. Greene (2010), 'Effects of healthy families New York on the promotion of maternal parenting competencies and the prevention of harsh parenting', Child Abuse \& Neglect, 34(10): 711-723. 
Romeo, R. R., J. A. Leonard, S. T. Robinson, M. R. West, A. P. Mackey, M. L. Rowe and J. D. E. Gabrieli (2018), 'Beyond the 30-million-word gap: children's conversational exposure is associated with language-related brain function', Psychological Science, 29(5): 700-710.

Rowe, M. L., S. W. Raudenbush and S. Goldin-Meadow (2012), 'The pace of vocabulary growth helps predict later vocabulary skill', Child Development, 83(2): 508-25.

Rubio-Codina, M. and S. Grantham-McGregor (2020), Validez predictiva de pruebas cortas comúnmente usadas para medir el desarrollo infantil en estudios a gran escala. Inter-American Development Bank Working Paper. DB-WP-1174.

Schilbach, F., H. Schofield and S. Mullainathan (2016), 'The psychological lives of the poor', American Economic Review, 106(5): 435-40.

Shah, A. K., S. Mullainathan and E. Shafir (2012), 'Some consequences of having too little', Science, 338 (6107): 682-685.

Shneidman, L. A. and S. Goldin-Meadow (2012), 'Language input and acquisition in a Mayan village: How important is directed speech?', Developmental Science, 15(5): 659-673.

Singh, L., S. Nestor, C. Parikh and A. Yull (2009), 'Influences of infant-directed speech in early word recognition', Infancy, 14: 654-666.

Smith, N. A. and L. J. Trainor (2008), 'Infant-directed speech is modulated by infant feedback', Infancy, 13 (4): 410-420.

Snow, C. E. and C. A. Ferguson (1977), Talking to children. Cambridge, UK: Cambridge University Press.

Soderstrom, M. and K. Wittebolle (2013), 'When do caregivers talk? The influences of activity and time of day on caregiver speech and child vocalizations in two childcare environments', PLoS One, 8(11): e80646.

Sperry, D. E., L. L. Sperry and P. J. Miller (2019), 'Reexamining the verbal environments of children from different socioeconomic backgrounds', Child Development, 90(4): 1303-1318.

Thaler, R. H. (2015), Misbehaving: The making of behavioral economics. New York: WW Norton.

The ManyBabies Consortium (2020). 'Quantifying sources of variability in infancy research using the infant-directed-speech preference', Advances in Methods and Practices in Psychological Science.

Weber, A., A. Fernald and Y. Diop (2017), 'When cultural norms discourage talking to babies: Effectiveness of a parenting program in rural Senegal', Child Development, 88(5): 1513-1526.

Weisleder, A. and A. Fernald (2013), 'Talking to children matters: early language experience strengthens processing and builds vocabulary', Psychological Science, 24(11): 2143-2152.

Zangl, R. and D. L. Mills (2007), 'Increased brain activity to infant-directed in 6-and 13-month-old infants', Infancy, 11(1): 31-62.

Zimmerman, F. J., J. Gilkerson, J. A. Richards, D. A. Christakis, D. Xu, S. Gray and U. Yapanel (2009), 'Teaching by listening: The importance of adult-child conversations to language development', Pediatrics, 124(1): 342-349. 


\section{Appendix 1: Correlations}

Figure A. Pearson Correlations between Manual and Automatic Annotations. Main Outcomes.

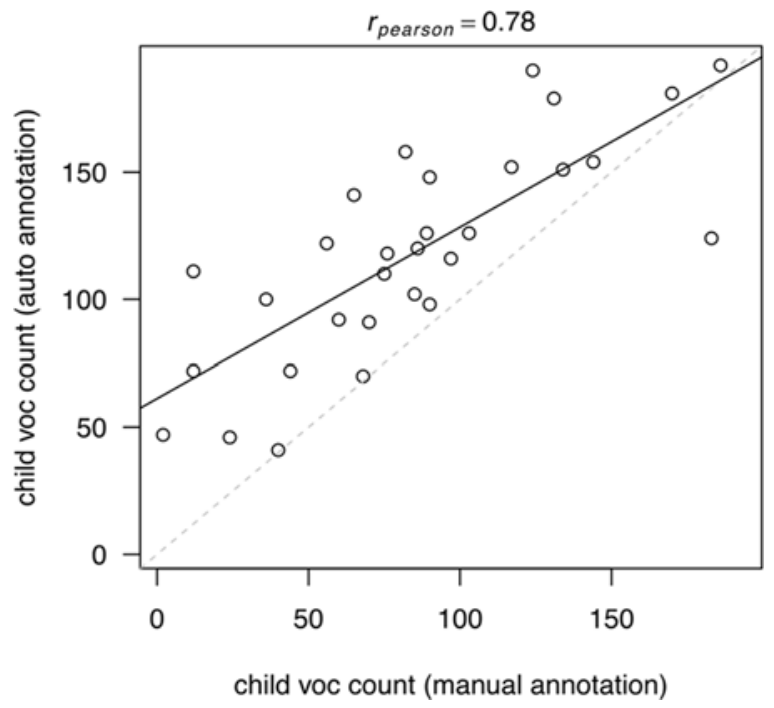

Figure A1. Count of Child Vocalizations.

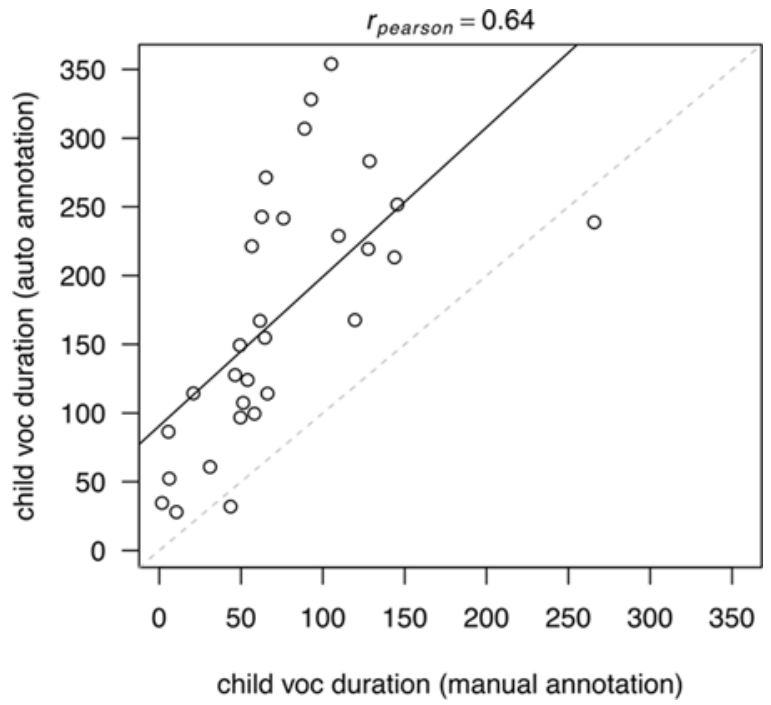

Figure A2. Duration of Child Vocalizations. 

Ana Balsa et al.

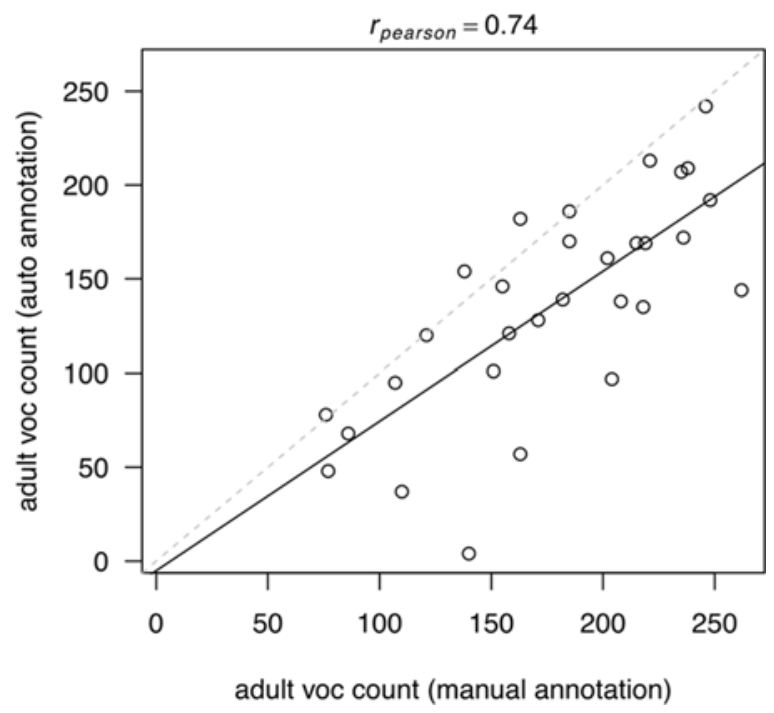

Figure A3. Count of Adult Vocalizations.

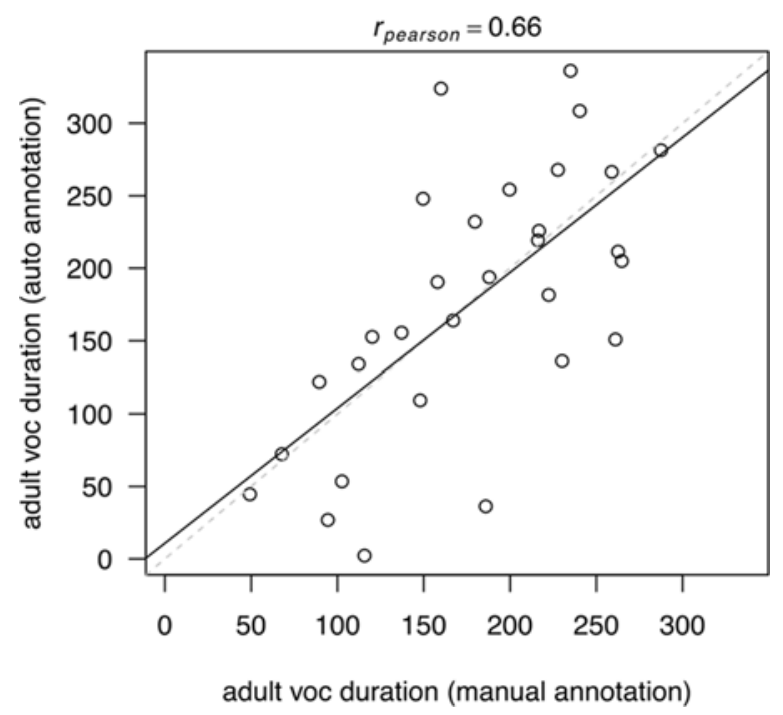

Figure A4. Duration of Adult Vocalizations. 


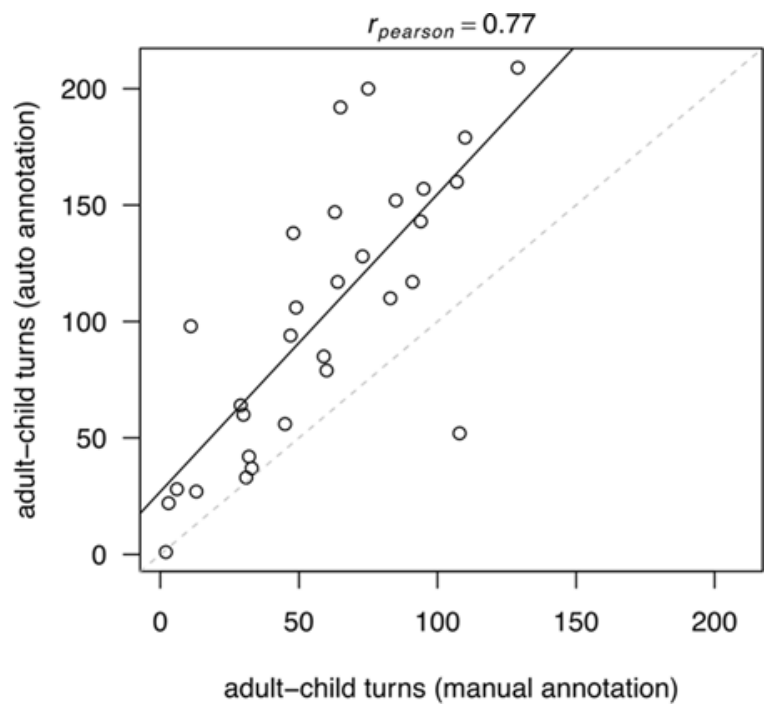

Figure A5. Adult-Child Turns.

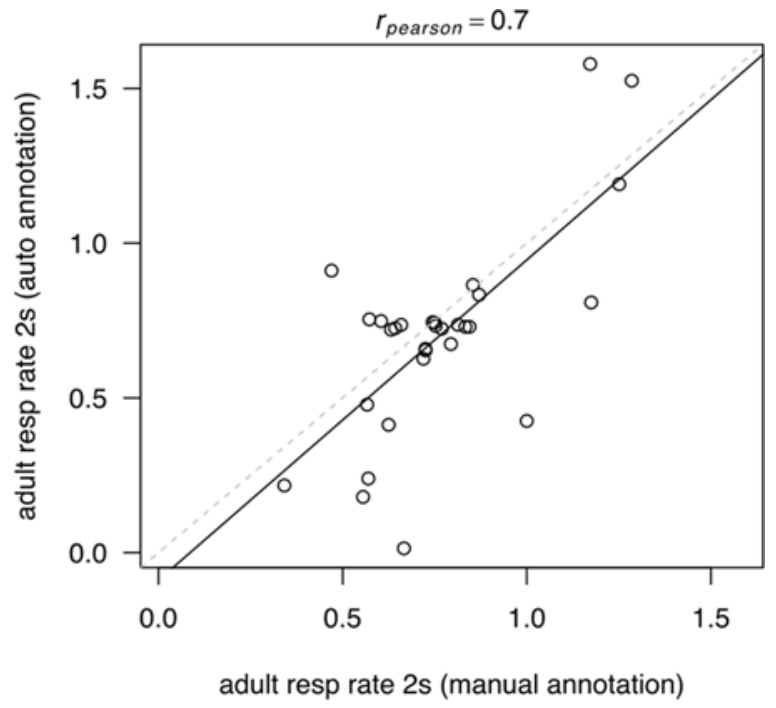

Figure A6. Adult Response Rate $2 \mathrm{~s}$. 


\section{Appendix 2:Robustness estimations}

Table A1. Pairwise correlations across outcomes

\begin{tabular}{|c|c|c|c|c|c|c|c|c|c|}
\hline & $\begin{array}{l}\text { Count of child } \\
\text { vocalizations }\end{array}$ & $\begin{array}{l}\text { Duration of } \\
\text { child } \\
\text { vocalizations } \\
\text { (s) }\end{array}$ & $\begin{array}{l}\text { Count of adult } \\
\text { vocalizations }\end{array}$ & $\begin{array}{c}\text { Duration of } \\
\text { adult } \\
\text { vocalizations }\end{array}$ & $\begin{array}{c}\text { Total } \\
\text { vocalization } \\
\text { duration }\end{array}$ & $\begin{array}{l}\text { Turns } \\
(0.3 \mathrm{~s})\end{array}$ & $\begin{array}{l}\text { Adult } \\
\text { response } \\
\text { ratio }\end{array}$ & $\begin{array}{c}\text { Adult } \\
\text { pitch } \\
\text { average }\end{array}$ & $\begin{array}{l}\text { Adult } \\
\text { pitch } \\
\text { range }\end{array}$ \\
\hline $\begin{array}{l}\text { Count of child } \\
\text { vocalizations }\end{array}$ & 1 & & & & & & & & \\
\hline $\begin{array}{l}\text { Duration of child } \\
\text { vocalizations (s) }\end{array}$ & $0.638^{\star \star \star}$ & 1 & & & & & & & \\
\hline $\begin{array}{l}\text { Count of adult } \\
\text { vocalizations }\end{array}$ & $0.177^{\star \star}$ & -0.123 & 1 & & & & & & \\
\hline $\begin{array}{l}\text { Duration of adult } \\
\text { vocalizations }\end{array}$ & -0.044 & $-0.192^{\star \star}$ & $0.840^{\star \star \star}$ & 1 & & & & & \\
\hline $\begin{array}{l}\text { Total vocalization } \\
\text { duration }\end{array}$ & $0.514^{\star \star \star}$ & $0.718^{\star \star \star}$ & $0.491^{\star \star \star}$ & $0.546^{\star \star \star}$ & 1 & & & & \\
\hline Turns (0.3 s) & $0.524^{\star \star \star}$ & $0.457^{\star \star \star}$ & $0.659^{\star \star \star *}$ & $0.594^{\star \star \star}$ & $0.811^{\star \star * *}$ & 1 & & & \\
\hline $\begin{array}{l}\text { Adult response } \\
\text { ratio }\end{array}$ & -0.0625 & -0.0367 & $0.805^{\star \star \star}$ & $0.838^{\star \star \star}$ & $0.563^{\star \star \star}$ & $0.709^{\star \star \star}$ & 1 & & \\
\hline Adult pitch average & -0.0355 & $-0.367^{\star \star \star}$ & 0.022 & -0.019 & $-0.326^{\star \star \star}$ & $-0.158^{\star \star}$ & -0.073 & 1 & \\
\hline Adult pitch range & $-0.181^{\star \star}$ & -0.0889 & $0.241^{\star \star \star}$ & $0.422^{\star \star \star}$ & $0.224^{\star \star \star}$ & $0.238^{\star \star *}$ & $0.396^{\star \star \star}$ & 0.031 & 1 \\
\hline
\end{tabular}

Notes: ${ }^{\star} p<0.1,{ }^{\star \star} p<0.05,{ }^{\star \star \star} p<0.01$. 
Table A2. TOT effects of CP messages on language outcomes

\begin{tabular}{|c|c|c|c|c|c|c|c|c|c|}
\hline & $\begin{array}{c}\text { Count of } \\
\text { child } \\
\text { vocalizations } \\
\text { (1) }\end{array}$ & $\begin{array}{l}\text { Duration of } \\
\text { child } \\
\text { vocalizations } \\
\text { (ss) } \\
\text { (2) }\end{array}$ & $\begin{array}{c}\begin{array}{c}\text { Count of } \\
\text { adult }\end{array} \\
\text { vocalizations } \\
\text { (3) }\end{array}$ & $\begin{array}{l}\text { Duration of } \\
\text { adult } \\
\text { vocalizations } \\
\text { (ss) } \\
\text { (4) }\end{array}$ & $\begin{array}{c}\text { Total } \\
\text { vocalization } \\
\text { duration (ss) } \\
\text { (5) }\end{array}$ & $\begin{array}{l}\text { Number of } \\
\text { turns } \\
\text { (threshold } \\
\text { of } 0.3 \mathrm{~s} \text { ) } \\
\text { (6) }\end{array}$ & $\begin{array}{l}\text { Adult } \\
\text { response } \\
\text { ratio } \\
(7)\end{array}$ & $\begin{array}{l}\text { Adult } \\
\text { pitch } \\
\text { average } \\
\text { (8) }\end{array}$ & $\begin{array}{l}\text { Adult } \\
\text { pitch } \\
\text { range } \\
(9)\end{array}$ \\
\hline TOT coefficient & -12.675 & $-46.451^{\star \star}$ & $14.170^{\star}$ & $39.898^{\star \star}$ & -6.709 & 4.954 & $0.064^{\star}$ & 0.134 & $0.504^{\star \star \star}$ \\
\hline TOT SE & $(7.851)$ & $(22.049)$ & $(8.372)$ & $(17.478)$ & $(27.358)$ & $(9.429)$ & $(0.037)$ & $(0.129)$ & $(0.147)$ \\
\hline $\begin{array}{l}\text { Wild bootstrapping } \\
\text { p-value }\end{array}$ & & [0.092] & [0.394] & {$[0.141]$} & & & {$[0.302]$} & & {$[0.021]$} \\
\hline$N$ & 159 & 157 & 159 & 159 & 157 & 159 & 157 & 158 & 158 \\
\hline
\end{tabular}

Notes: ${ }^{\star} p<0.1,{ }^{\star *} p<0.05,{ }^{* * *} p<0.01$. 
Table A3. ITT effects of CP messages on language outcomes in the last $300 \mathrm{~s}$ of video

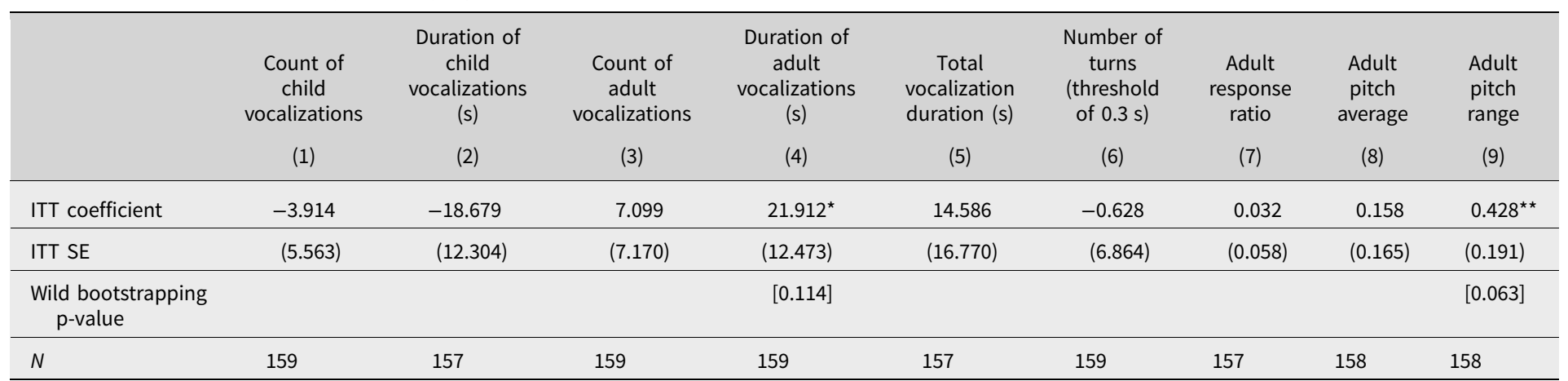

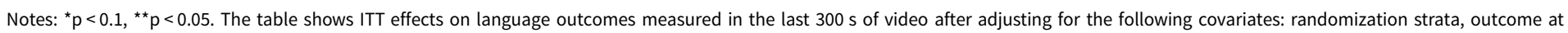
baseline, mother's education, mother's age, child's gender, child's age in months when the intervention began, the number of months that elapsed between the final assessment and the date when the intervention began, the number of people in the household, single child, whether the father worked full time at baseline, and indicators for the timing when the family was videotaped at baseline (in August 2017, in November-December 2017, or both). When there are two baseline measures, we use the average. Robust standard errors are reported in parentheses. For significant outcomes, we report in squared brackets the p-value on the ITT coefficient after adjusting standard errors for clustering around centers using wild bootstrapping. 
Table A4. ITT effects on a larger sample with videos at follow-up

\begin{tabular}{|c|c|c|c|}
\hline Outcomes & $\begin{array}{l}\text { Duration of child } \\
\text { vocalizations } \\
\text { (1) }\end{array}$ & $\begin{array}{l}\text { Duration of adult } \\
\text { vocalizations } \\
\text { (2) }\end{array}$ & $\begin{array}{l}\text { Adult pitch } \\
\text { range } \\
\text { (3) }\end{array}$ \\
\hline \multicolumn{4}{|c|}{ (1) Adjusting for SES $(N=274)$} \\
\hline ITT coefficient & $-28.968^{*}$ & 8.641 & $0.299^{\star \star \star}$ \\
\hline ITT SE & $(16.211)$ & $(13.661)$ & $(0.114)$ \\
\hline $\begin{array}{l}\text { Wild bootstrapping } \\
\text { p-value }\end{array}$ & {$[0.298]$} & & {$[0.143]$} \\
\hline \multicolumn{4}{|c|}{ (2) Adjusting for SES + inverse probability weighting $(N=247)$} \\
\hline ITT coefficient & $-41.776^{\star \star}$ & 4.042 & $0.257^{\star \star}$ \\
\hline ITT SE & $(17.028)$ & $(14.743)$ & $(0.125)$ \\
\hline $\begin{array}{l}\text { Wild bootstrapping } \\
\text { p-value }\end{array}$ & {$[p=0.173]$} & & {$[p=0.201]$} \\
\hline
\end{tabular}

Notes: ${ }^{\star} p<0.1,{ }^{\star \star} p<0.05,{ }^{\star \star \star} p<0.01$. The table shows the effects of randomization into treatment (ITT) on language outcomes using a larger sample with videos at follow-up but not necessarily at baseline. Regressions adjust for the following set of covariates: randomization strata, mother's education, mother's age, child's gender, child's age in months when the intervention began, the number of months that elapsed between the final assessment and the date when the intervention began, the number of people in the household, single child, and whether the father worked full time at baseline. Robust standard errors are reported in parentheses. For significant outcomes, we report in squared brackets the $p$-values after adjusting standard errors for clustering of observations around centers using wild bootstrapping (WB p).

Cite this article: Balsa A, López Boo F, Bloomfield J, Cristia A, Cid A, Ferro MP, Valdés R, González ML (2021). Effect of Crianza Positiva e-messaging program on adult-child language interactions. Behavioural Public Policy 1-37. https://doi.org/10.1017/bpp.2021.25 